\title{
Review
}

\section{Review on Additive Manufacturing of Multi-Material Parts: Progress and Challenges}

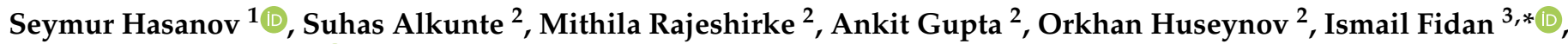 \\ Frank Alifui-Segbaya ${ }^{4}(\mathbb{D})$ and Allan Rennie ${ }^{5}$
}

check for updates

Citation: Hasanov, S.; Alkunte, S.; Rajeshirke, M.; Gupta, A.; Huseynov, O.; Fidan, I.; Alifui-Segbaya, F.; Rennie, A. Review on Additive Manufacturing of Multi-Material Parts: Progress and Challenges. J. Manuf. Mater. Process. 2022, 6, 4 https://doi.org/10.3390/ jmmp6010004

Academic Editors:

George-Christopher Vosniakos,

Alborz Shokrani and

George Chryssolouris

Received: 22 November 2021

Accepted: 13 December 2021

Published: 27 December 2021

Publisher's Note: MDPI stays neutral with regard to jurisdictional claims in published maps and institutional affiliations.

Copyright: (C) 2021 by the authors. Licensee MDPI, Basel, Switzerland. This article is an open access article distributed under the terms and conditions of the Creative Commons Attribution (CC BY) license (https:// creativecommons.org/licenses/by/ $4.0 /)$.
1 College of Professional Studies, The University of Alabama in Huntsville, Huntsville, AL 35899, USA; seymur.hasanov@uah.edu

2 Department of Mechanical Engineering, Tennessee Tech University, Cookeville, TN 38505, USA; ssalkunte42@tntech.edu (S.A.); mcrajeshir42@tntech.edu (M.R.); agupta42@tntech.edu (A.G.); ohuseynov42@tntech.edu (O.H.)

3 Department of Manufacturing and Engineering Technology, Tennessee Tech University, Cookeville, TN 38505, USA

4 School of Medicine and Dentistry, Gold Coast Campus, Griffith University, Southport, QLD 4222, Australia; f.alifui-segbaya@griffith.edu.au

5 Department of Engineering, Faculty of Science and Technology, Lancaster University, Lancaster LA1 4YW, UK; a.rennie@lancaster.ac.uk

* Correspondence: ifidan@tntech.edu; Tel.: +1-931-372-6298

\begin{abstract}
Additive manufacturing has already been established as a highly versatile manufacturing technique with demonstrated potential to completely transform conventional manufacturing in the future. The objective of this paper is to review the latest progress and challenges associated with the fabrication of multi-material parts using additive manufacturing technologies. Various manufacturing processes and materials used to produce functional components were investigated and summarized. The latest applications of multi-material additive manufacturing (MMAM) in the automotive, aerospace, biomedical and dentistry fields were demonstrated. An investigation on the current challenges was also carried out to predict the future direction of MMAM processes. It was concluded that further research and development is needed in the design of multi-material interfaces, manufacturing processes and the material compatibility of MMAM parts.
\end{abstract}

Keywords: multi-material additive manufacturing; functionally graded materials; conventional manufacturing; interface issues

\section{Introduction}

Additive manufacturing (AM) is an emergent technology with potentials to transform conventional manufacturing. AM processes help to reduce the need for tooling and provide flexibility in design and product customization as compared to conventional processes [1-6]. Recent advances in AM processes have enabled the fabrication of multi-material structures with complex geometry and parts with various materials that display different thermal, chemical and physical properties [7-10].

The advantages of manufacturing components with multiple materials with different chemical and physical properties are key for the successful production of customized mechanical components with tailored performance characteristics. Multi-material AM (MMAM) methods have recently been applied to fabricate complex structures in an efficient way to save production time and the cost of the materials used [11-16]. With the advantage of fabricating multiple materials in a single manufacturing process, it is possible to produce functionally graded materials (FGM) with improved material interface characteristics. With the help of MMAM, arbitrarily complex and locally controlled FGMs can easily be fabricated. A number of previous attempts have mainly focused on ceramic-metal 
structures [17], metal composites fabricated by selective laser melting (SLM) [18,19], wirearc $[20,21]$ and other laser deposition processes [22,23]. Recently, advances in material jetting processes have enabled the control of the material deposition on a voxel scale [24-26]. With the help of these technologies, the spatial distribution of mechanical properties can be controlled over very small dimensions. However, the limitation of materials and cost of these technologies reduce the benefits of the current FGM fabrication. A simplistic outline highlighting the general material combinations based on suitable material type and possible material property improvement is presented in Figure 1.

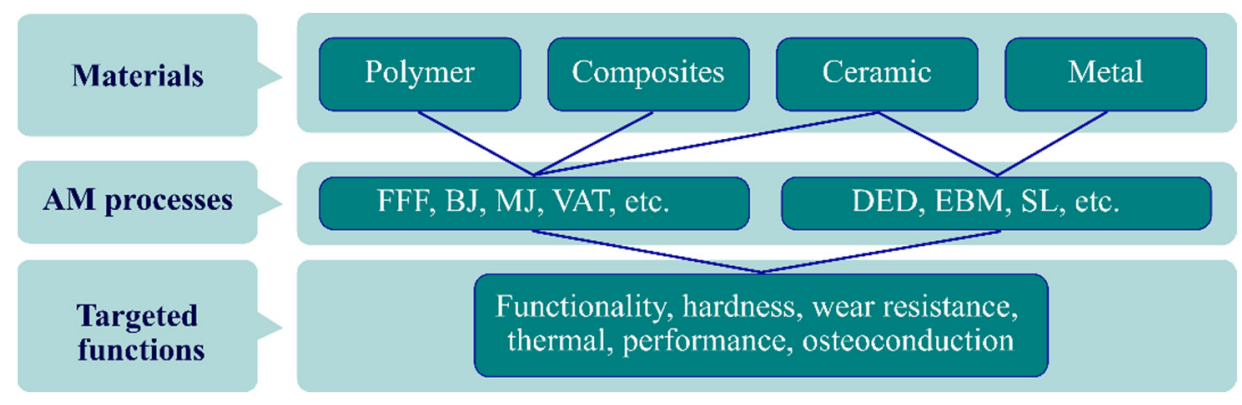

Figure 1. Overview of manufacturing and property enhancement possibilities of MMAM.

Multiple material combinations of real structures widely exist in nature. Therefore, the fabrication of multi-material parts using a low-cost manufacturing process is desirable. MMAM enables the manufacture of highly complex parts with site-specific properties without using costly and time-consuming conventional processes. Multi-material parts can be fabricated with graded regions that provide property gradients over the volume that can be used for damping, thermal gradients, fracture resistance, and construction materials. Based on these implementations, it is of great interest to fabricate multi-material parts using AM technologies. Therefore, investigation of the existing literature is an important step to identify the current advantages and limitations of MMAM, which enables the prediction of the future trend of the technology and its possible applications. Figure 2 provides examples of multi-material parts fabricated using different manufacturing processes.

MMAM has been explored in recent years with a variety of processes and methods. Recently, Ituarte et al. conducted research on the design and fabrication of functionally graded structures through multi-material binder jetting technology [27]. One unique research study performed by Garland et al. investigated the fabrication of multi-material structures with optimal material distributions [28]. Another research study was performed by Dorcas et al., who used the voxel-based multi-material deposition process to fabricate FGM components for tensile tests [26]. Moreover, Doubrovski et al. manufactured a prosthetic socket that consisted of various material combinations [24]. Some research studies investigated multi-material parts made by AM technology where the material joining region had direct contact. Brischetto et al. conducted research to fabricate a sandwich panel using an AM method [29]. In that study, external layers were produced with acrylonitrile butadiene styrene (ABS), while an internal core was produced using polylactic acid (PLA) material using the multi-extruder fused filament fabrication process. Lopez et al. also investigated the mechanical behavior of tension test specimens made of PLA, ABS and high-impact polystyrene (HIPS) material combinations [30]. The results show that producing sandwich structures with a PLA-ABS-PLA material arrangement led to a higher mechanical behavior than other design combinations. Some studies reported the combination of polymer-metal and ceramic multi-material parts via the laser powder bed fusion technique [31,32]. 

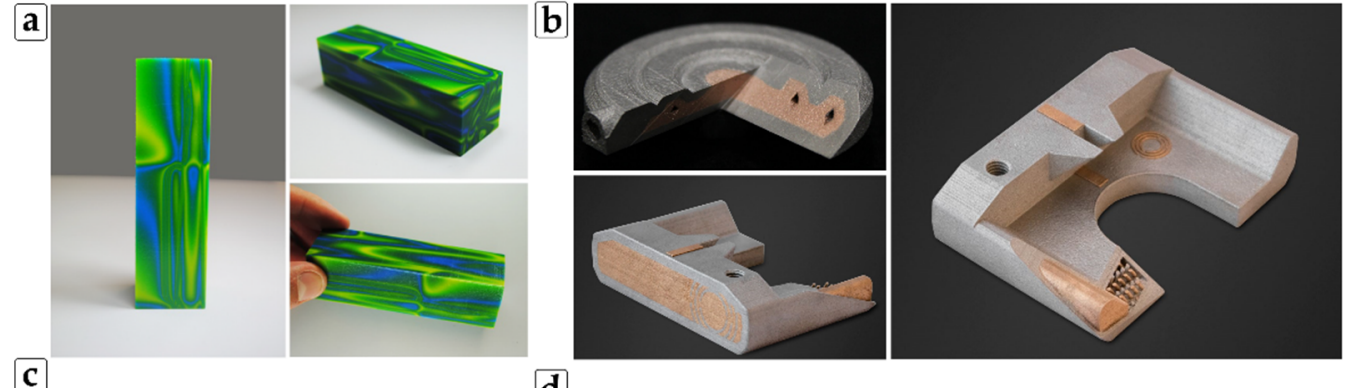

$\mathbf{C}$

d

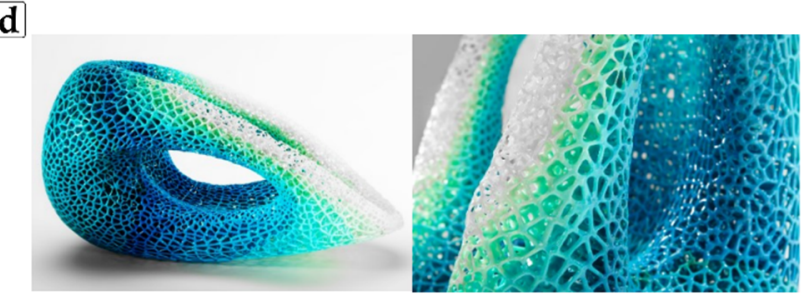

e
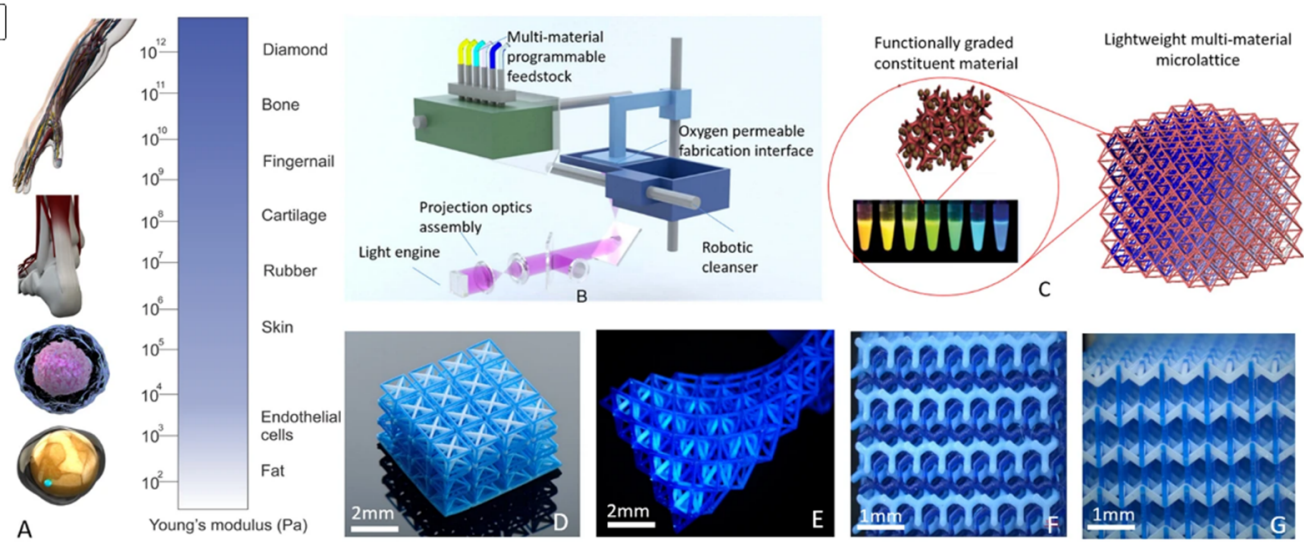

Figure 2. (a) Volumetric gradient pattern of VeroCyan and VeroYellow polymer materials fabricated by the Stratasys PolyJet J750, reproduced with permission from [33], (b) dual-metal copper parts created using Aerosint's recoater, photo by Aerosint, reproduced with permission from [34], (c) multi-material part generated by the Paramatters software and fabricated by the AM technology, reproduced with permission from [35], (d) 3D-printed multi-material lattice chair fabricated by the Stratasys Object 500 Connex 3 with gradient material interfaces, image adopted from [36], (e) fabrication of 3D multi-material microlattice with dissimilar constituent materials. Images were reprinted for free with no permission required under http:/ / creativecommons.org/licenses/by/4.0/ through article (accessed on 20 November 2021) [37].

The purpose of the literature review is to explore the current research studies associated with the fabrication of multi-material parts using AM methods. In addition to the very latest published research, this review explores the conventional multi-material part fabrication techniques, potential materials used, AM processes and their application areas. This paper also outlines the importance of FGM fabrication with the help of MMAM processes.

\section{Conventional Methods of Fabricating Multi-Material Parts}

Witnessing the advantages of multi-material approaches for part manufacture confirms that there is a need to generate different combinations of materials [38,39]. These multi-material parts or structures need to be carefully designed and evaluated to take full advantage of their use. Various conventional manufacturing (CM) methods are already available to join at least two different materials. They are still popular because of the many advantages they present. Spot welding, drilling, riveting, die casting and extrusion are some of the CM methods widely used in producing multi-material parts [40]. The CM processes presented in Figure 3 are significantly different to AM processes due to their shaping operations. In casting, a hollow mold of the desired shape is filled with a molten metal or 
alloy. Machining produces workpieces made with subtractive steps through automation. In forging, raw stock materials (also known as billets) are reshaped with compressive dies. The joining process involves fusing or connecting two or more components for the purpose of making a new part.

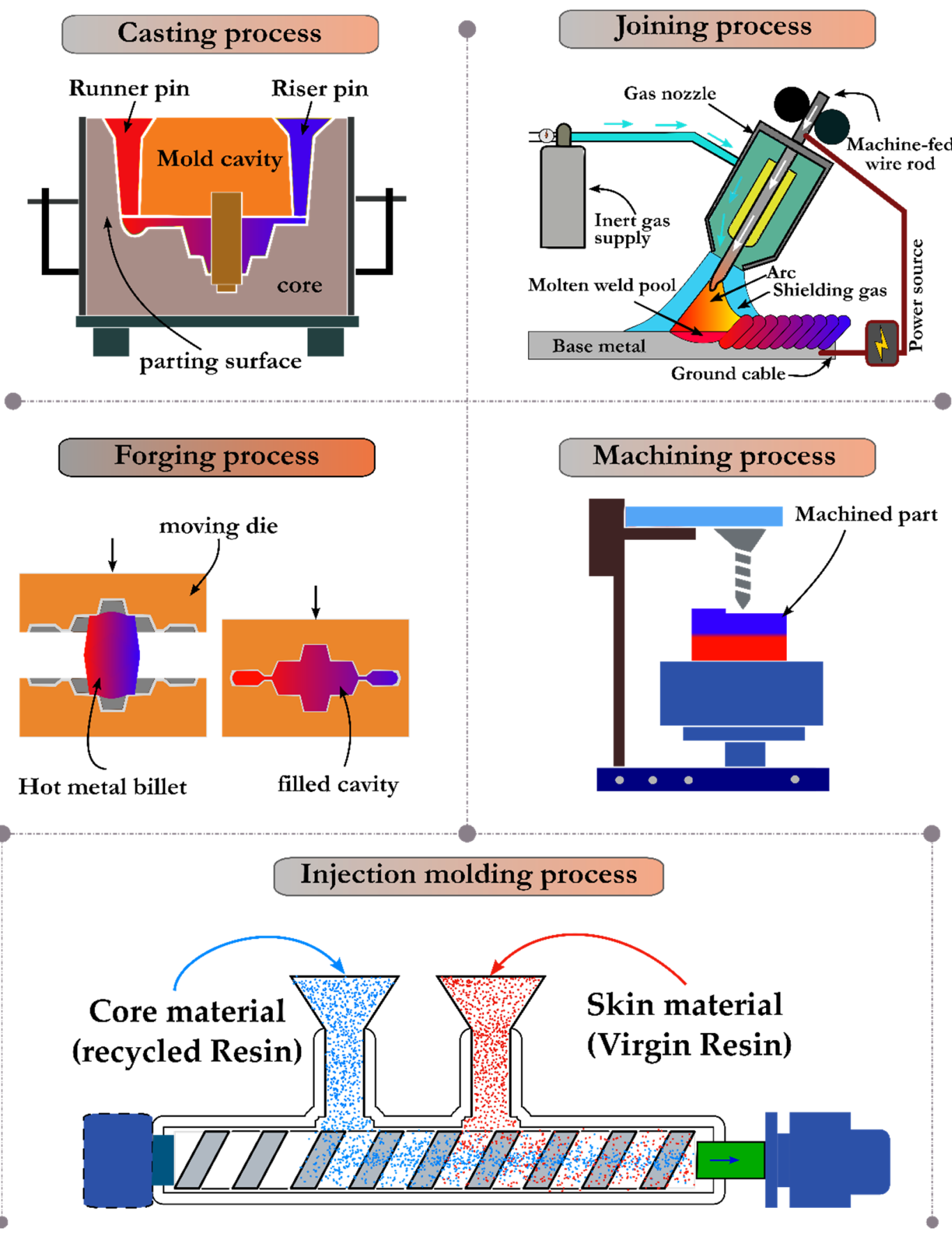

Figure 3. Schematic of casting, joining, forging, machining and injection molding processes.

\subsection{Casting Process}

Metal casting is one of the oldest and simplest processes for producing near net shape products. This process requires a mold cavity of the desired shape and molten metal to pour into the mold cavity, usually sand molds [41]. Classical foundry is still a relevant technique for producing large functional parts (e.g., engine blocks, gears and chassis) despite advances in big area additive manufacturing [42]. The build parameters of currently available metal 
3D printers and perhaps the physics behind the different AM processes also limit the production of large parts. Using a foundry provides an advantageous solution if there is a need to produce multiple copies of parts. The cost of producing many parts will equally reduce. In contrast, the use of AM could increase the production cost even with reduced labor. Priyadarshi et al. used the in-mold assembly technique to perform the multi-material part manufacturing. Injection molding is a technique that involves melting different polymer materials at their melting point and forcing the resultant substance into a mold to achieve the desired shape, as shown in Figure 3. Full assembly of the structure can be produced without the use of other joints such as bolts, glue, welds and fasteners [43]. Casting materials are usually metals or various time setting materials that cure after mixing two or more components together; examples are epoxy, concrete, plaster and clay.

Casting is ideal for complex parts that would otherwise be challenging or uneconomical to construct with other manufacturing methods. For instance, machine tool beds and ship propellers are better cast than joined [42]. In the work of Gouker et al., they successfully applied multi-material molding to different types of compliant joints by combining mold piece joints that provided a degree of freedom ranging from 1 to 3 [44].

In general, AM processes allow the fabrication of highly complex, customized, lightweight and hollow parts with higher precision, good surface finish, dimensional accuracy and various infill densities. Post processing operations required for some AM processes are much easier and quicker than casting processes. Metal casting always requires extra material removal to cut out the feed head and filling system.

\subsection{Joining Process}

The multi-material combination technique is very useful in automobile sectors. Steel is a widely used material in car manufacturing; however, due to its heavy weight factor, there is a significant need to employ different materials to reduce the weight. Joining is considered one of the $\mathrm{CM}$ processes that allow the fusing or connecting of two or more components for the purpose of making a new part, as shown in Figure 4. Overall, these processes connect two or more components permanently. They also require the use of separate tools. Some of the commonly used joining processes are welding and soldering. Joining two different materials is a key technology that can play a significant role in the development of lightweight vehicles. Meschut et al. investigated various welding technologies for combining different materials to create multi-material structures, establishing the mechanical-thermal joining of dissimilar metals using resistance element and friction element welding [45]. Similarly, high mechanical strength at the interface was achieved by mechanically joining the two materials using friction stir welding [46]. The cost of making any metal AM component is always higher than any joining process. The conventional welding of soldering processes are very cost-effective solutions. Post processing is an essential part of any AM and joining processes. There are still no manufacturing methods introduced to eliminate the need of heat treating, grinding and deburring yet.

Monolithic design

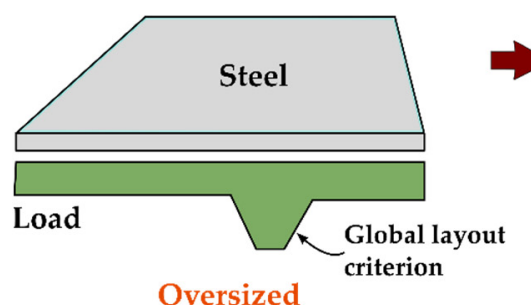

Oversized
Multi-material design

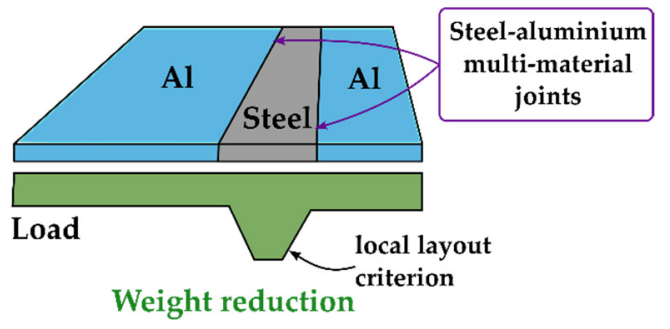

Figure 4. Example of a multi-material design using welding process. 


\subsection{Forging Process}

Complete material consumption, high strength, better surface quality and short lead times can be achieved using the forging technique for multi-material part fabrication. Forging is one of the oldest manufacturing processes that shapes the raw stock material by applying compressive dies on it. Based on the temperature at which the operation is performed, the process can be classified as "hot forging", "warm forging" or "cold forging". Wohletz et al. used the cold and warm forging techniques to combine steel and aluminum for manufacturing multi-material products. The study concluded that to provide significant bonding between the steel billet and aluminum billet, the initial temperature should reach up to $450{ }^{\circ} \mathrm{C}$ and $100^{\circ} \mathrm{C}$, respectively [47]. The forging process improves the mechanical properties of the raw stock material by refining its grain structure, providing a good grain flow, making it tougher and stronger by the end. Behrens et al. combined two $\mathrm{CM}$ processes to fabricate multi-material parts. They performed the thermo-mechanical treatment in order to attain grain refinement in the welded materials using the forming process. This led to the enhancement of the mechanical properties of the final multi-material part [48]. Parts produced by forging have excellent mechanical properties with minimum waste. Through minimal waste and cost, the original material is plastically deformed to the desired geometric shape for targeted and improved mechanical properties [41]. The main advantage of forging versus AM is the fabrication of large-size objects with less time and cost. However, continuous research on AM will lead to the more economical fabrication of large-size objects with ease in near future.

\subsection{Machining Process}

Machining is a manufacturing process in which a raw stock material is cut to a desired final shape and size by a controlled material removal operation [49]. Today, computer numerical control (CNC) is more commonly used due to its advantages in precision and automation and its better surface finish. CNC manufacturing is the process of producing machined workpieces with computerized manufacturing techniques. Although numerical control is the original name given to this technology, it is still used interchangeably with CNC. These CM processes are the most common methods in subtractive manufacturing. In these processes, the final geometry of the workpiece is formed by removing material from the raw stock material. CNC operations use the same G code logic as AM processes. However, their function is to cut the object in order to shape the final geometry [50]. CNC machining processes many kinds of material (i.e., metal, plastic, wood, ceramic or composite) to meet specifications by following a coded programmed instruction without a manual operator directly controlling the machining operation [51]. Compared to CNC manufacturing, in AM, complex shapes can be fabricated with ease and in both processes the time it takes to produce a component is dependent on the complexity, size, height and volume for each process. One of the main advantages of AM in comparison with CNC machining is the possibility of creating completely hollow, lightweight and chapter objects with less material waste.

\subsection{Limitations of Conventional Manufacturing of Fabricating Multi-Material Parts}

CM processes usually take separate components and combine them during post processing to produce composite parts. However, in general, MMAM uses a single manufacturing process to make composite parts. Although there are advantages of CM, various disadvantages also need to be addressed. The cost and quality of the finished workpiece are the main factors that need to be considered when selecting the CM technique for multimaterial part generation. Conventional methods require a lot of investment in terms of consumables and logistics. CMs also consume more energy to fuse the materials together, which adds on to overall costs. Joining the materials with casting leads to a higher cost because of its heavy initial investment, consumables for post processing, etc. [40]. Quality is also another factor to be considered for the case of multi-material part fabrication. Welding dissimilar materials leads to poor quality at the interface and hence needs to be addressed 
critically. The processing time is also a big issue in CMs, most of which involve a long setup time and the movement of bulky devices, which increases the processing time.

\section{Current Multi-Material Additive Manufacturing Processes}

MMAM technology is becoming ever more popular in industrial and research communities. Layer by layer, material is added to build the desired structure to form a solid 3D model. The raw material used to produce the parts includes metals, thermoplastics, hydrogels, ceramics, composites, hybrids and functionally graded materials in liquid, powder and solid forms. MMAM has several advantages over traditional manufacturing processes, including minimal material wastage, lightweight production, low-cost processes and its ability to easily fabricate complex shapes, along with being affordable and environmentally friendly. Each MMAM technology has its own pros and cons, among them low dimensional accuracy, the size limitation of components, a limited range of materials, required post processing, inefficiency for large volumes and requirements for specific environments. MMAM technology is relevant in diverse applications for industrial sectors such as aerospace, automotive, healthcare, construction and food processing as well as in research and academic institutions [39,52]. Broadly, MMAM technology is divided into seven categories: material extrusion, vat photopolymerization, powder bed fusion, material jetting, direct energy deposition, sheet lamination, binder jetting and hybrid additive manufacturing.

\subsection{Material Extrusion (ME)}

$\mathrm{ME}$ is one of the most well-known AM processes that uses various materials such as thermoplastics [53,54], composites [55-57], metal-filled thermoplastic filaments [58-60] and flexible elastomers [61] to make components in a layer-by-layer fashion. Figure 5 provides a schematic representation of the fused filament fabrication (FFF) process, which is one of the subcategories of ME that utilizes thermoplastic filament. Filament material is melted inside the extrusion head and deposited onto a build plate using a bead-by-bead and layer-by-layer technique. The main advantage of this process is the availability of a large selection of materials and the easily customizable process to produce tailored multimaterial structures [28,62]. The development and advancement of the modern technologies make it possible to manufacture multiple-material parts in a single manufacturing process. Khondoker et al. [63] designed a static mixer inside the extrusion nozzle head of the FFF machine, which aimed to help mix the two different polymers during the deposition process. The authors revealed that intermixed specimens could increase the interface strength of FFF-made parts. Similarly, Zachary et al. [64] designed an extrusion system with a dynamic mixer inside the extrusion head of the FFF machine. This addition helped to blend the polymer martials consistently and improved the mixing quality of the polymers. These studies show that the static and dynamic mixing of two polymer materials could affect the interface strength of multi-material parts. Advantages of the FFF process include its fast-processing time, a wide variety of material selection and its low-cost nature. The disadvantages of the multi-head FFF technique are the inherently poor surface quality of the parts, limited printing resolution, slow fabrication time and weak interface strength.

\subsection{Material Jetting (MJ)}

Material jetting is one of the most efficient and precise AM methods. The working principle of MJ is the same as conventional printing machines. Micro droplets are deposited layer by layer on the build platform. The fabrication of multiple materials in a single structure is well established in MJ process. In this process, several photo-curable materials are processed using a jetting head. Each of these heads has many tiny nozzles, which allow the printing of multiple materials simultaneously with a high resolution [65-67]. The MJ process enables the production of high-resolution materials, which is one of the main limitations of other AM processes. Figure 6 highlights a schematic description of this method. 


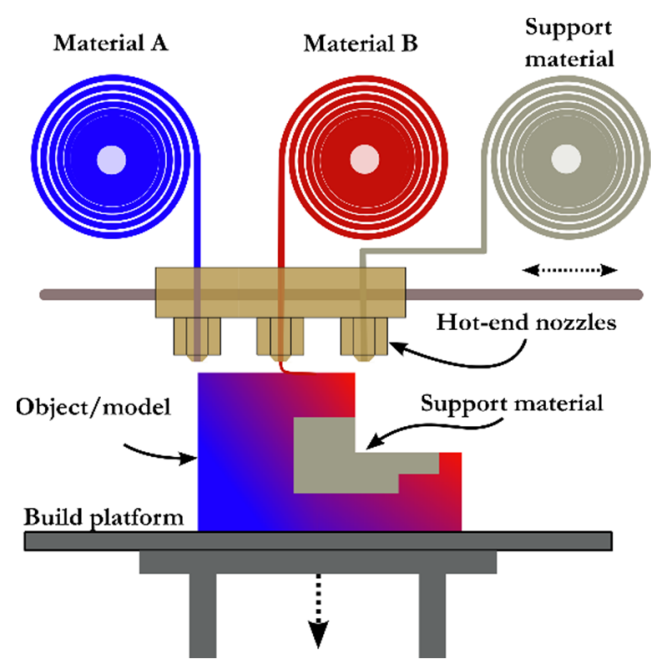

Figure 5. Process description of FFF process.

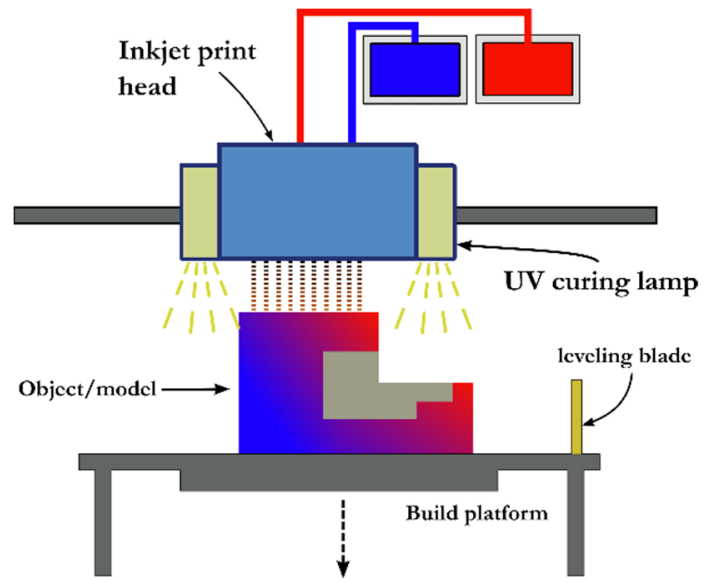

Figure 6. Process description of MJ.

Several research studies were performed to fabricate multi-material parts using the MJ process. Vu et al. $[67,68]$ fabricated acrylic photopolymers using the MJ process to study the fracture behavior of the material interfaces. In this study, elastomeric (TangoBlackPlus) and acrylic (VeroWhitePlus) materials were processed to produce fracture specimens. It was found that failures mainly occurred at the material interface zones. The results also show that gradient material interfaces could easily be achieved in this process, which eventually enhance the joint strength of the two material components. The advantages and disadvantages of this process are shown in Table 1.

Table 1. Advantages and disadvantages of MJ process $[66,69,70]$.

\section{Advantages}

Easy fabrication of complex geometries Faster printing time of multiple materials High dimensional accuracy

Parts can be built in a variety of materials with multiple inkjet nozzles

Multiple materials can be fabricated with higher resolution

Parts have homogeneous mechanical and thermal properties Low material waste due to accurate jetting

\section{Disadvantages}

Limited selection of materials

Expensive process

Higher material cost

Poor mechanical properties of the materials

MJ materials are photosensitive and mechanical properties degrade overtime

Most parts still require support materials Mainly used for non-functional prototypes 


\subsection{Direct Ink Writing (DIW)}

DIW is one of the simplest and most easily accessible processes amongst MMAM methods. This process allows the use of a wide range of materials to fabricate multiplematerial structures with low manufacturing and material cost. Although the process operation is similar to FFF, DIW does use a heating source to produce parts. The materials used in this process are introduced in their liquid form rather than solid. The material is mixed using a rotating impeller and comes through the nozzle when pressure is applied [71]. Figure 7 shows a schematic description of the DIW process.

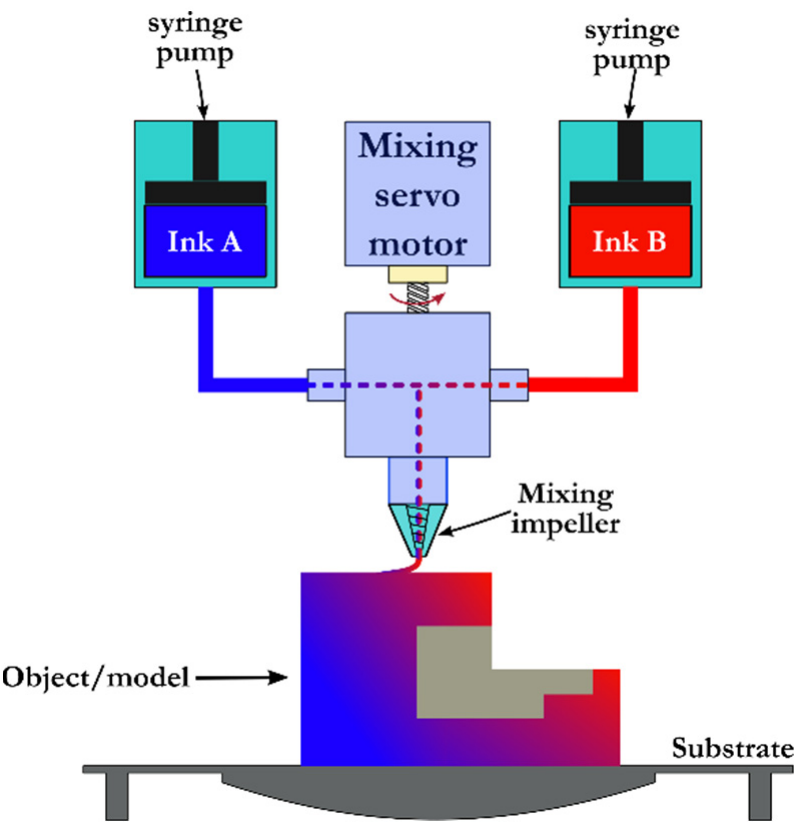

Figure 7. Process description of DIW.

The benefit of this process is the availability of a large selection of materials including materials with biological [72,73], structural [74,75] and electrical properties [76,77]. The drawback of the DIW technique is the use of a sequential fabrication process for each material, which slows down the entire manufacturing time. To overcome this challenge, a single-nozzle DIW system has been developed recently [78]. It allows the fabrication of multi-material structures using a single-nozzle extrusion head based on the adjustable ratio of the material deposition. Moreover, the material mixing process can be improved with the addition of the mixer into the extrusion head, which can increase the homogeneity and uniformity of the material blends $[25,79]$. This allows the operator to quickly switch material blending ratio during the deposition process. The material blending ratio can also be varied, which enables the deposition of FGMs with tailored thermo-mechanical properties. However, changing the material ratio requires more time, and printing extra artifacts increases the production cost and creates material waste. These are still challenges that need to be addressed in the future. Figure 8 highlights a DIW system that was configured to mix materials inside the extrusion head to fabricate ceramic carbide specimens. Tailored heterogeneity was achieved using an in-line mixing system. 

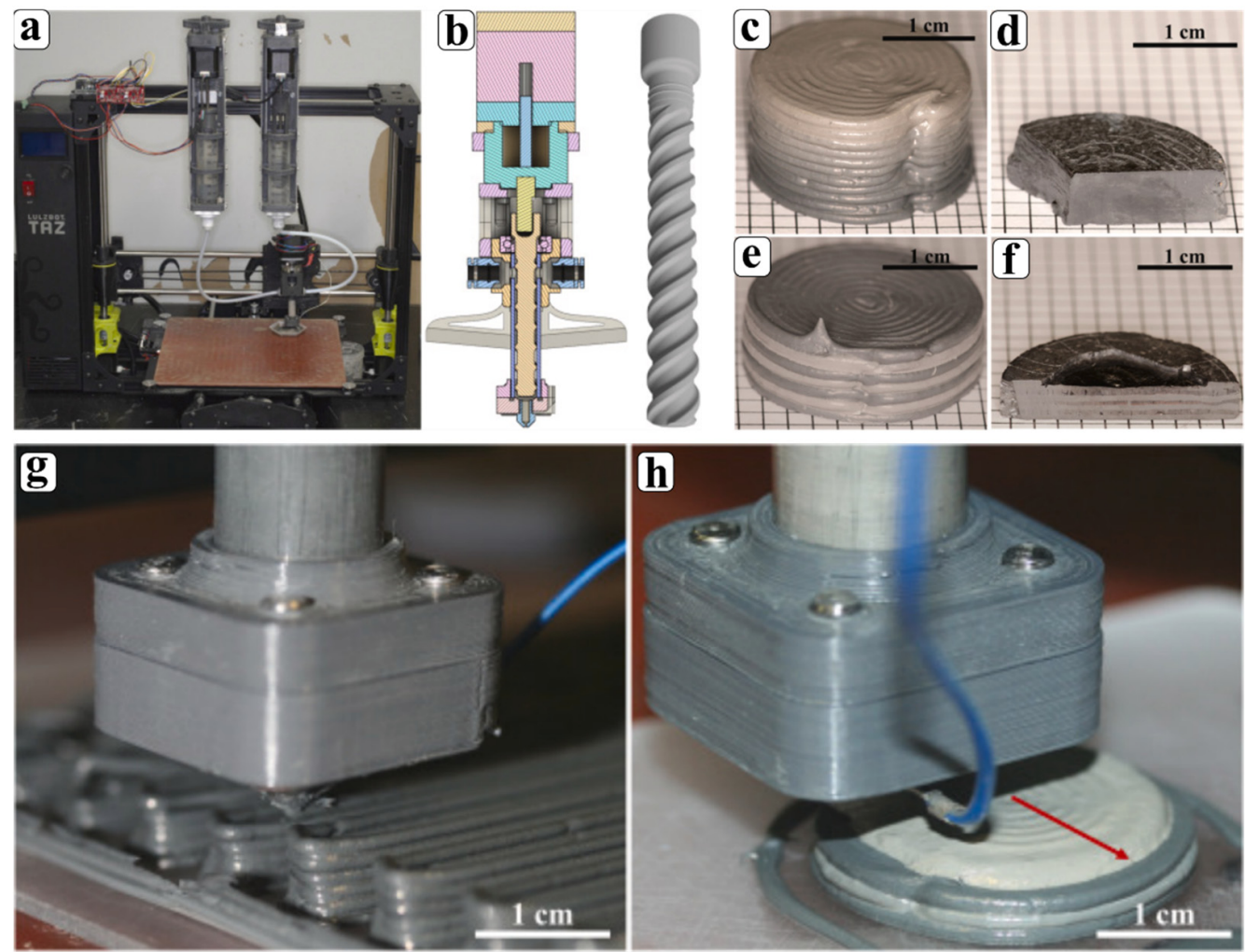

Figure 8. (a) DIW system mounted on LulzBot 6 printer, (b) cross-section of the extrusion head, (c) continuous gradient printing in green states, (d) sintered states, (e) a sharp transition pattern of ceramic carbide specimen in green state, (f) in sintered state; light and dark inks are $\mathrm{SiC}$ and $\mathrm{B}_{4} \mathrm{C}$, respectively, (g) deposited $\mathrm{B}_{4} \mathrm{C}$ ink stacks indicate good shape retention, (h) inside-out concentric infill patterns were found to reduce printing related defects over rectilinear infill patterns. All images reproduced with permission, Copyright (C) 2021 [80].

\subsection{Vat Photopolimerization (VAT)}

The VAT process through stereolithography (SLA) uses photopolymer resin to fabricate materials with high resolution and better surface quality as compared to other AM processes $[81,82]$. Photopolymerization is the curing process that occurs when UV light is exposed to deposited material and cross connections between polymer chains develop, causing the deposited material to transition from a liquid or semi-solid to a solid state. Figure 9 shows a schematic description of the VAT process. Fabricating multi-material parts using this method requires material exchange from one liquid resin to another inside the vat. This process increases the manufacturing time and is extremely laborious [83]. The use of multiple materials in VAT process creates challenges in managing contamination between materials. However, automating this technique to fabricate multi-material parts was recently proposed [84]. In this process, swapping between materials was automated using a rotating carousel system. Multiple vats filled with liquid resin were mounted on a rotating platform. At the time of material change, the required vat is rotated to the fabrication platform, where the laser power is used for further processing. The pros of this process include the high dimensional accuracy of the final component and transparent material fabrication. The major drawbacks of this process include the requirement of extra time to change between materials, limitation to only photopolymers, material contamination and possible waste in the process. 


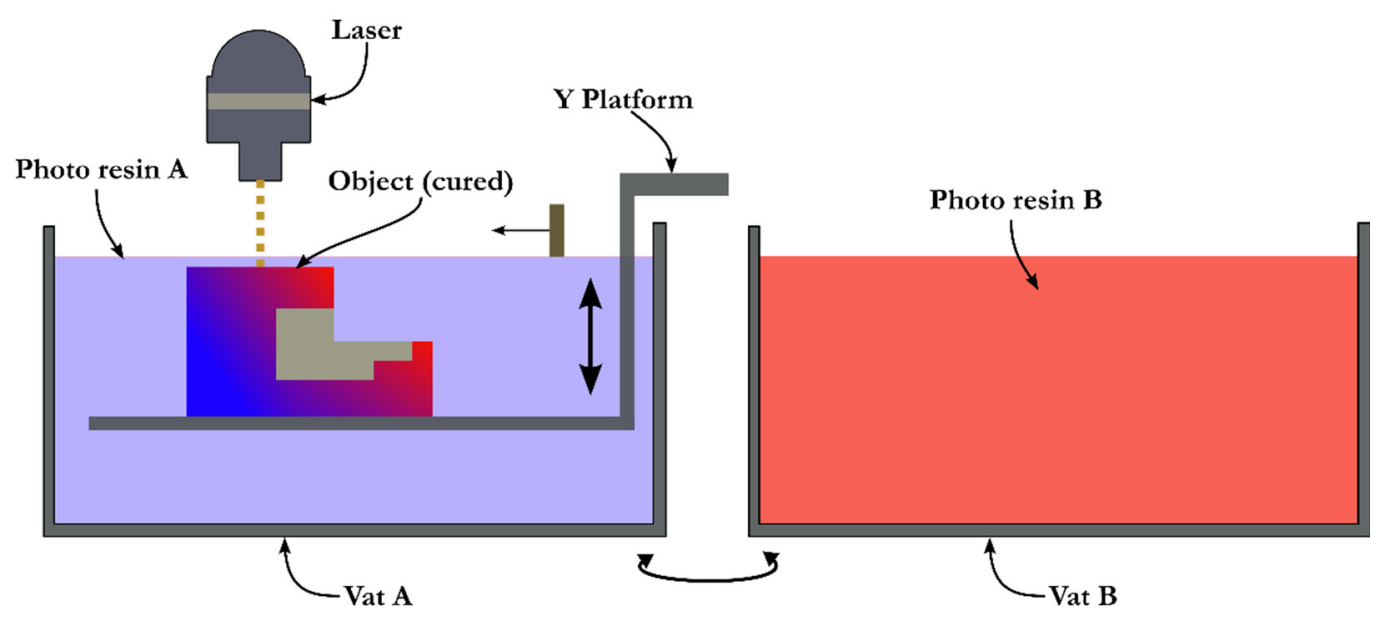

Figure 9. Process description of VAT.

\subsection{Direct Energy Deposition (DED)}

Lately, metal-based AM methods have evolved to produce direct fabrication of heterogeneous components with full spatial material distributions [85-87]. DED is one of the MMAM methods that falls into different processing categories, such as laser metal deposition (LMD), laser engineered net shaping (LENS) and direct metal deposition (DMD) [86]. In this process material is used in the form of wire or powder. Materials are melted using laser, electron beam or plasma arc energy sources in the controlled region. In this process inert gas is used to prevent the oxidation of the molten pool. In the DED process, powder material is blown through deposition nozzles where it is melted and deposited layer by layer on the substrate, which then solidifies. The nozzle has a multi-axis arm and moves around the object [88]. This procedure includes the use of a variety of materials such as metal wire and powder, ceramics, functionally graded materials (FGM), metal-matrix composites (MMC) and coatings [39]. In this technique, powders are deposited at a specific time of build by changing their types dynamically. Figure 10 shows the schematic description of the DED process with multi-material capability. The advantage of this process is the ability to change powders at any time during the manufacturing process. Additional pre-mixed powders can also be added without interrupting the fabrication process. Another benefit of the DED technique is the possibility of gradual changes in the material deposition process, which enable the creation of FGM structures with tailored material properties [89].

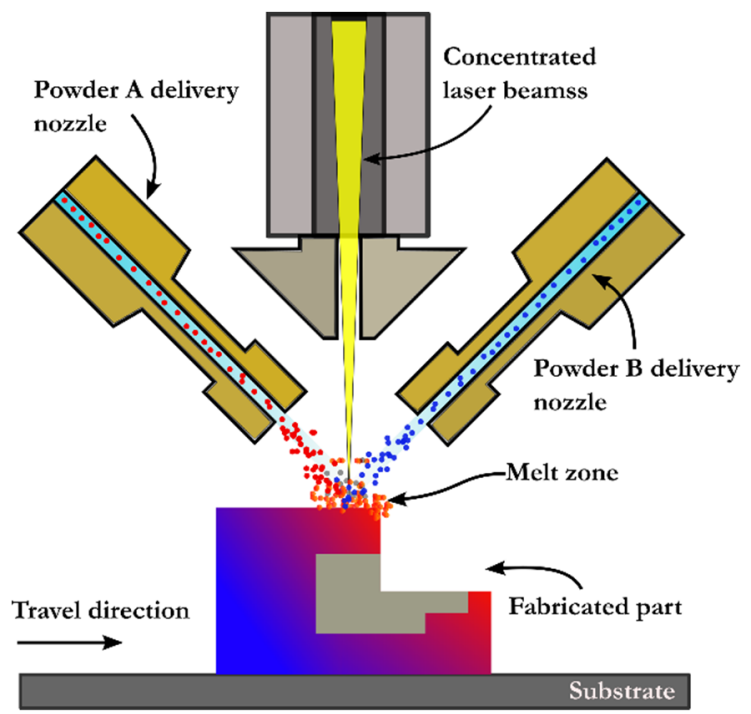

Figure 10. Process description of depositing multiple materials using DED process. 
The fabrication of multi-material parts using the DED process has been extensively studied among researchers. Recently, Ke et al. [90] studied on the compositionally graded doped hydroxyapatite coating on titanium using laser and plasma spray deposition techniques for the fabrication of bone implants. This study revealed an innovative way of enhancing mechanical and antibacterial properties of plasma-sprayed HA coating interfaces for load-bearing orthopedic as well as dental implant applications. In another study, Yan et al. [85] optimized the process parameters on multi-materials, i.e., the fabrication of cermet composite using Inconel 718 and ceramic powders. The results show that in-housebuilt software helped to reduce energy usage and material waste while increasing powder melting. Detailed studies have been reported in the literature on the use of DED for the fabrication of multi-material structures. Research studies showed that laser engineered techniques can be used to produce metallic multi-material parts with high strength and good surface quality [91-93]. The main advantage of the DED process is the availability of a wide range of materials, and material interfaces can be produced with high strength. The disadvantages of this process include the low dimensional accuracy of the printed parts, residual thermal stress, requirement of atmospheric control and machining process, which is important for finishing the part.

\subsection{Hybrid Additive Manufacturing}

The term hybrid additive manufacturing (HAM) describes the combination of two or more different processes and machines. The primary goal of this method is to overcome the limitations of MMAM techniques and to improve quality and productivity [94]. Figure 11 shows AM techniques combining FFF, DIW and MJ [95]. In general, HAM combines the cost-saving AM process with dimensionally accurate subtractive process such as CNC machining. Since extensive material waste occurs during the CNC machining process, HAM enables reduced material waste while maintaining the dimensional accuracy of the machined parts. In HAM techniques, first the AM (the DED process is mainly used) process is used to manufacture a part, and then conventional manufacturing techniques are used to increase the surface quality of the final part. Lately, DMG MORI's Lasertec 125 3D hybrid system was released, which is a HAM process that creates, maintains and repairs workpieces up to $1250 \mathrm{~mm}$ wide and $750 \mathrm{~mm}$ high, weighing up to $2000 \mathrm{~kg}$ [96]. This system uses a five-axis material fabrication and five-axis milling process within the same machine. It is noteworthy that automatic shifting between laser deposition welding and simultaneously five-axis milling in a single manufacturing process reduces fabrication time by up to 80 percent. Another HAM machine was introduced by Optomec, which uses CNC milling, lathes, robotic operation and more into one process, creating high quality components by providing precise motion control during the production process [97]. The limitations of this process are the use of CNC machining operations in overhanging areas of the printed parts, the time it takes to change tools, and the huge amount of preprocessing considerations [98]. Overall, Table 2 shows the advantages and disadvantages of the subtractive and additive processes. Figure 11 depicts the process description of HAM method.

Table 2. Comparison of additive and subtractive processes.

\begin{tabular}{ll}
\hline \multicolumn{1}{c}{ CNC Machining } & \multicolumn{1}{c}{ Direct Energy Deposition } \\
\hline Repeatable & Less material waste \\
Precise & Geometry freedom \\
Good surface finish & Material Combos \\
High productivity & Longer cycle-times \\
Wasteful & Poor Surface Finish \\
\hline
\end{tabular}


a

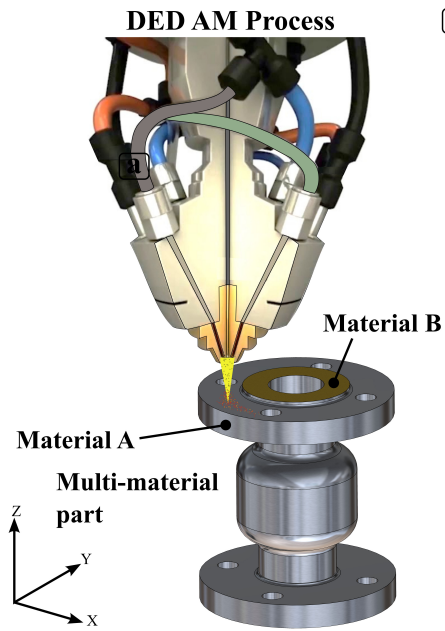

(b)

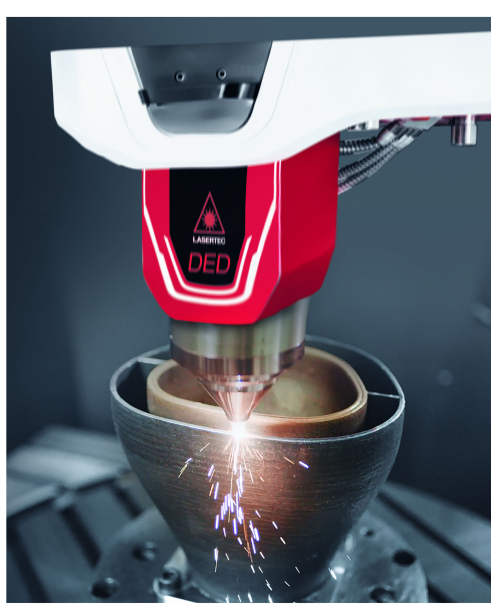

(c) CNC Machining

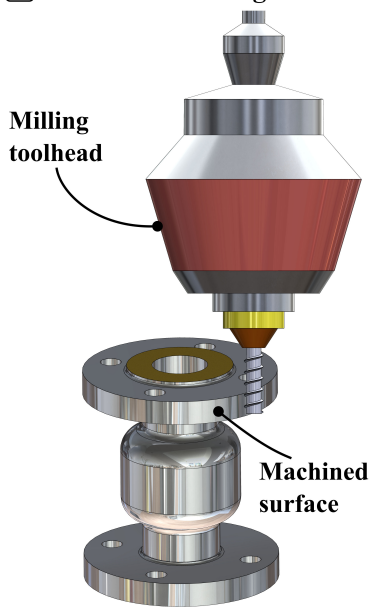

d

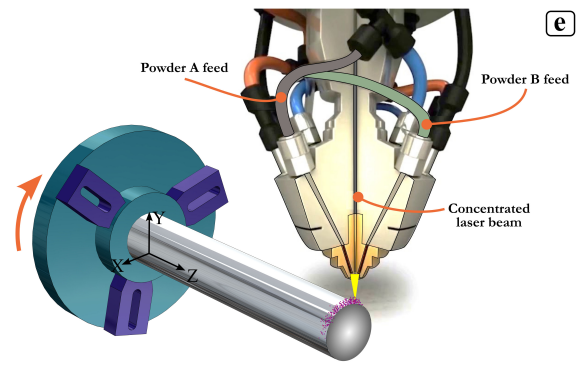

e

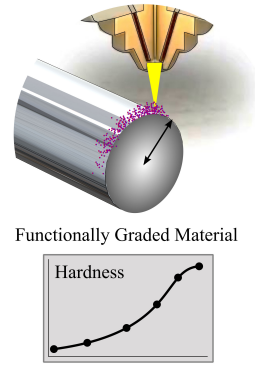

f

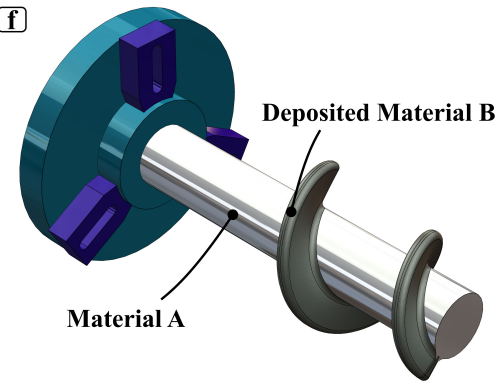

Figure 11. Hybrid AM system which combines DED and CNC machining processes: (a) fabrication of multi-material part with the help of DED process, (b) multi-material heat exchanger fabricated by Lasertec 125 by DMG MORI, reproduced with permission, Copyright @ 2021 [96], (c) CNC machining process to increase the surface quality of the part, (d) performing DED process on the shaft to fabricate functionally graded material, (e) FGM-fabricated part with various hardness properties, (f) deposition of second material during turning process.

\subsection{Functionally Graded Additive Manufacturing (FGAM)}

Functionally graded additive manufacturing (FGAM) is a layer-by-layer fabrication process that intentionally modifies the processing parameters and gradually changes the spatial material distribution within one component to meet the intended function [99]. The main goal of using FGAM is to produce performance-based freeform components driven by their gradual change in the material properties. In the case of FGMs, they are fabricated with the FFF process. The FGAM workflow is shown in Figure 12.

MMAM is revolutionary because its applications provide new opportunities for FGMs in aerospace, automobile and medical industries $[17,18,100]$. The interface of multi-material structures can be fabricated by varying volume concentrations of the materials in a continuous step using a single machine that enables the fabrication of composite parts directly from the design stage to functional parts. Materials are combined in a single process to produce polymer-polymer, metal-metal and polymer-composite combinations at desired locations [101].

Currently, the fabrication of multi-material parts using separate nozzles for each material limits the capability of printing FGM components because of direct interface transition. Since a sharp transition at material joints can show high-stress concentrations, the part will show weaknesses under various stress states. This limitation is controlled by utilizing a single-nozzle extruder that enables the change of composition continuously while printing based on the adjustable ratio of the extruder motor. The advantage of the FGAM process over conventional AM is swapping materials without changing the extrusion head $[9,28,101,102]$. Figure 12 describes the entire FGAM workflow from the design of FGM components to their fabrication and characterization stage. 


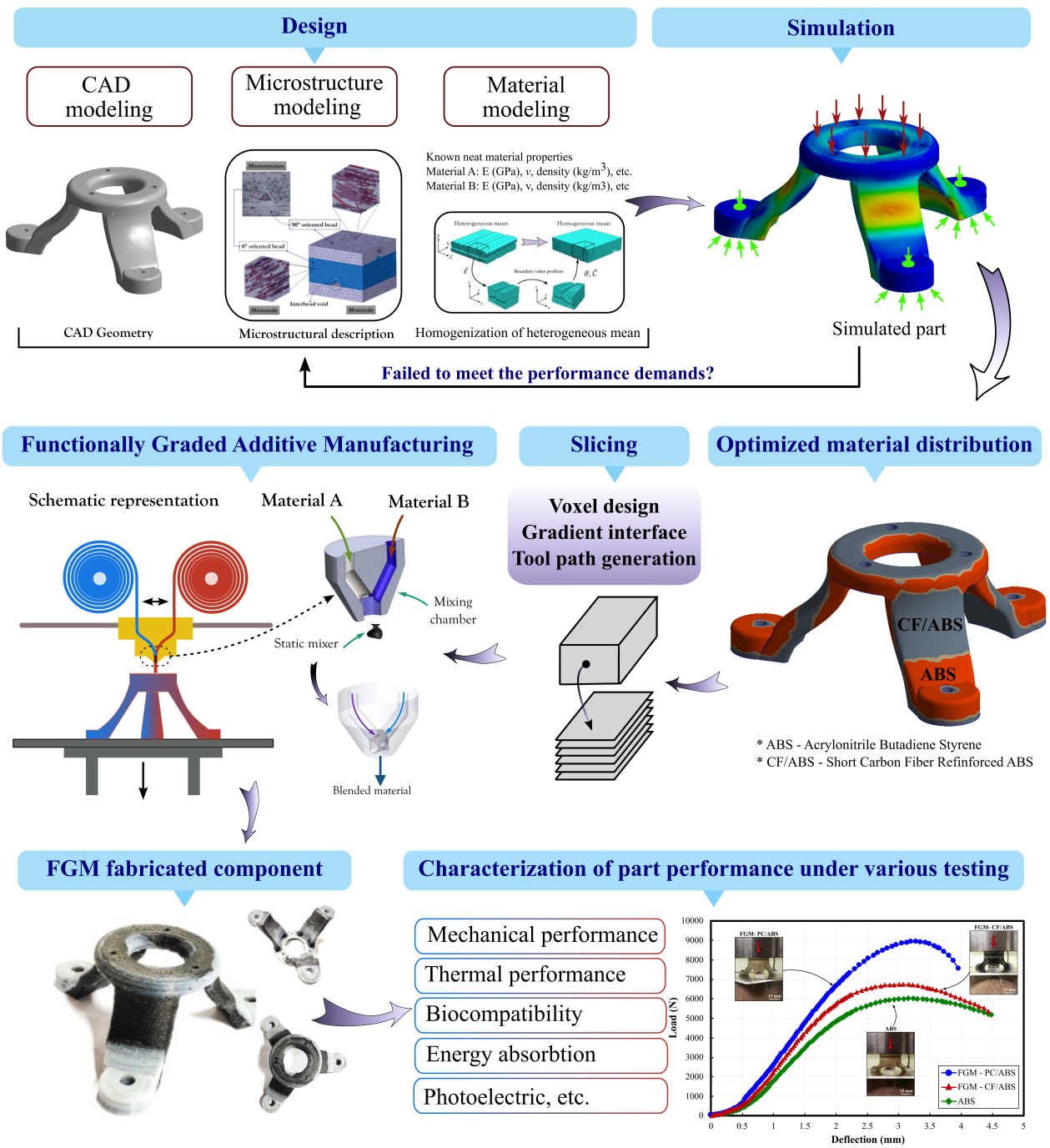

Figure 12. Functionally graded additive manufacturing workflow $[101,102]$.

The FGAM process workflow involves several steps, including design modeling (geometrical modeling, microstructural modeling and materials modeling), simulation, the optimization of material distribution, slicing and tool path generation, 3D printing, in situ material characterization and performance analysis $[16,101,103]$. Since most AM-made parts have anisotropic material properties due to the heterogeneities created during the fabrication process, homogenizing material properties is therefore necessary. This needs to be performed at the initial stage of the material design process. Another important step is the slicing and tool path generation, which involves converting a mesh model into small voxels for material characteristics' allocation and tool path slicing. After part fabrication, various testing methods are applied to characterize part performance for desired functionality.

The accelerating capabilities of AM processes necessitate enhancement of existing CAD programs to assess optimal material allocation and distribution in MMAM parts. Typical CAD workflow is best suited to conventional manufacturing, which requires basic using shapes and modification processes to create 3D objects. However, in multi-material components, a dedicated CAD package is required to explicitly allocate materials at desired locations within the part volume to tailor its functionality.

GraMMaCAD is a CAD program developed by the Computer Graphics Research of Fraunhofer Institute for multi-material parts with locally defining material properties. As a graphical interactive tool, it is used for augmenting 3D models stemming from commercial CAD systems with FGM information to be manufactured with corresponding 
AM technology. It also overcomes the current limitations of many CAD systems that are based on boundary representations and provides user-friendly interface to add FGM information to the interior of CAD geometry. Moreover, Fraunhofer conducts research in alternative volumetric representation schemes to integrate geometric modeling and simulation (IGA) [104] and multi-material 3D printing [105]. Figure 13 shows a sample part, with a custom-designed interface from hard to soft material, designed using GraMMaCAD and fabricated with the help of multi-material 3D printer.
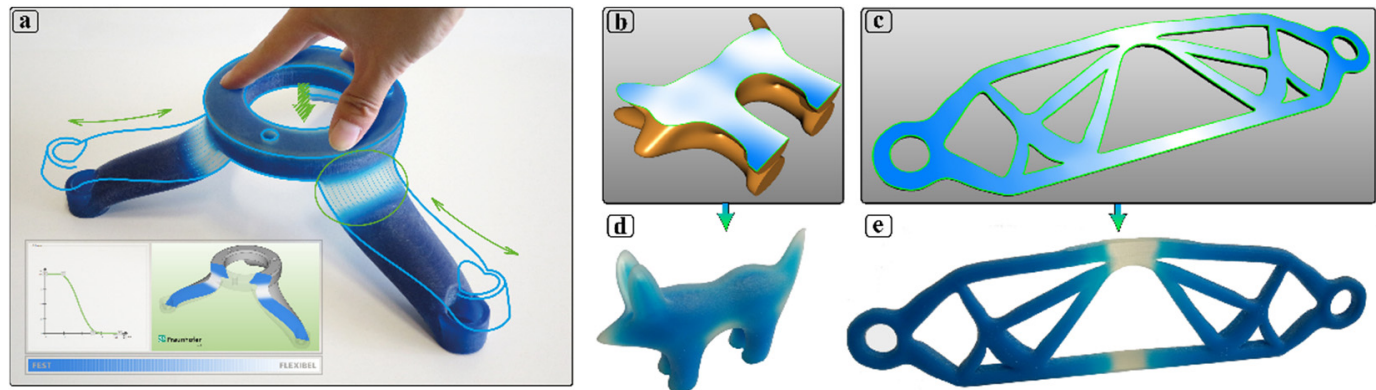

Figure 13. CAD models can be augmented with functionally graded material transitions (e.g., from stiff to flexible): (a) The stand produced by multi-material 3D printing damps and cushions components mounted to it, reproduced with permission [104], (b,c) cut through models, e.g., cayote and topology optimized model, respectively (green lines are slicing contours), (d,e) fabricated objects with gradient material interfaces based on volumetric models, all images are reproduced with permission, Copyright @ 2019 [105].

Although FGAM is relatively new, it is growing rapidly in popularity. When it is fully developed, software companies and research institutions will be able to provide the manufacturing industry with the needed design approach and solutions.

\section{Materials Used to Fabricate Multi-Material Parts with AM Technologies}

Different materials for fabricating multi-material AM parts have been documented and studied in the literature $[61,63,106]$. Zhangwei et al. [107] provided a review on various ceramic materials and their properties and applications. To build MMAM objects, achieving an optimal bond between the materials is fundamental to their performance. Noteworthily, there are variations in MMAM delivery systems and bonding processes for the various materials and techniques. Figure 14 shows material classifications used in MMAM. Many materials have been studied in the context of MMAM materials. The following is a summary of these materials and the studies that have been conducted to understand their properties. In the first section pure thermoplastics are covered. Secondly, composites and finally metals and alloys are discussed.

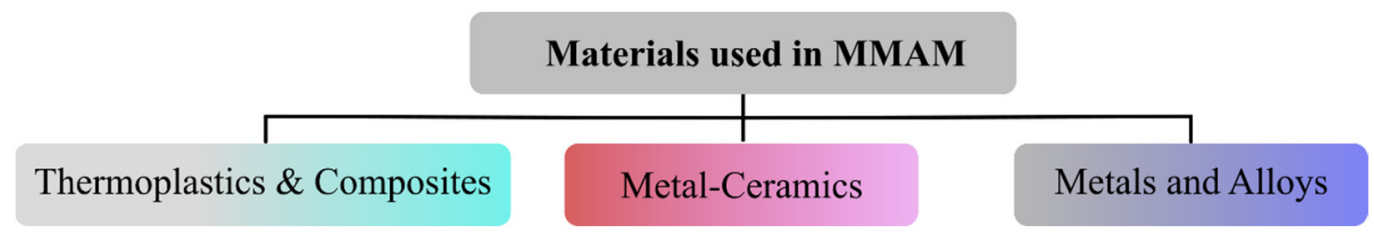

Figure 14. Material categories used in MMAM.

\subsection{Thermoplastic Polymers and Composites}

A combination of various thermoplastic materials has been extensively studied in MMAM. Thermoplastic materials have a variety of applications in medical, automotive and aerospace industries due to their relatively easier processing conditions compared to those of metals $[8,44,45,84]$. Among various polymers, PLA is the most widely used plastic filament material in 3D printing. It is the most extensively researched, utilized, 
biodegradable and renewable aliphatic polyester. The production of PLA has numerous advantages; it is biodegradable, biocompatible, recyclable, compostable and eco-friendly as its production consumes carbon dioxide. Sudhir Kumar et al. presented an investigation dealing with the optimization of printing conditions of FDM for PLA/PA6-TiO2 -based matrix for medicinal applications. Multi-layered components of different materials were printed successfully and tested for various mechanical, rheological, thermal, and surface characteristics. From thermal analysis, it was concluded that the polymeric matrices of PLA and PA6- $\mathrm{TiO}_{2}$ are thermally stable for the two repeated cycles of heating and cooling. Additionally, peak strength was greater for these material combinations than for pure PLA [108]. One of the widely used polymer material is ABS because of its favorable mechanical properties, such as impact resistance, toughness, and rigidity, when compared with other polymers. Additionally, it can be modified for improved impact resistance, toughness and heat resistance [109-112]. Ranvijay et al. studied multi-material printing of primary recycled ABS, PLA and HIPS in composite form [113]. Thermal (glass transition temperature and heat capacity) and mechanical properties (break load, break strength, break elongation, percentage elongation at break and Young's modulus) were analyzed to observe the behavior of multi-material composites. Arash et al. used multi-material 3D printing to deposit an ASA coating on the surface of ABS structures to protect against UV radiation, moisture and heat [114]. It was observed that ASA coating provides good protection for the underlying ABS specimen. Janusz Kluczynski et al. focused on the examination of the internal quality of joints created in MMAM process [115]. PLA and ABS were used for making different combinations of joints, i.e., 1-Monolithic, PLA; 2Pleated connection, PLA; 3-Overlap connection, PLA; 4-Monolithic, ABS; 5-Pleated connection, ABS; 6-Overlap connection, ABS; 7-Overlap connection, PLA/ABS; 8Overlap connection, PLA/ABS. The study revealed that the samples with an "overlap" joint have greater strength than specimens with a "smooth" joint.

Another widely used thermoplastic material in MMAM is nylon, which obtains highstrength, good temperature resilience, abrasion resistance and chemical stability [1]. Nylon describes a family of synthetic polymers composed of polyamides. It is a silk-like thermoplastic, generally made from petroleum products processed into fibers, films or shapes. Nylon polymers can be mixed with additives to meet different manufacturing requirements. M. A. Wagner et al. studied three classes of hinges using aramid, polyamide and photopolymer materials that were fabricated by different AM processes [116]. The aramid hinge showed an exceptionally high ultimate line load, outperforming the other two hinge classes investigated. However, the fatigue resistance was very low due to the deformation mode of the composite. Otepbergenov et al. performed a numerical simulation to determine the high stress concentrations of the ankle-foot orthosis model made by PLA [117]. Nylon was incorporated into the 3D-printed model to reduce high stress concentrations. Other thermoplastic materials used in MMAM are summarized in Table 3.

Table 3. Thermo-mechanical properties of various materials used in MMAM.

\begin{tabular}{|c|c|c|c|c|c|c|}
\hline Material & Density $\left(\mathrm{g} / \mathrm{cm}^{3}\right)$ & $\begin{array}{l}\text { Youngs Modulus } \\
\text { (GPA) }\end{array}$ & $\begin{array}{l}\text { Tensile Strength } \\
\text { (MPA) }\end{array}$ & $\begin{array}{l}\text { Glass Transition } \\
\text { Temperature }\left({ }^{\circ} \mathrm{C}\right)\end{array}$ & $\begin{array}{c}\text { Melting } \\
\text { Temperature }\left({ }^{\circ} \mathrm{C}\right)\end{array}$ & $\begin{array}{c}\text { Printing } \\
\text { Temperature } \\
\text { Range }\end{array}$ \\
\hline ABS & & 2.28 & 43 & & $200-250$ & 210-250 [118] \\
\hline PLA & $1.21-1.25$ [119] & & $21-60$ [119] & $45-60$ [119] & $150-162$ [119] & $190-230[118]$ \\
\hline $\mathrm{PC}$ & $1.21[55]$ & $2.57[55]$ & - & 140 [55] & $270[55]$ & $260-310$ [118] \\
\hline PEEK & 1.32 [120] & & $90-100$ [120] & 143 [120] & 343 [120] & $360-420[118]$ \\
\hline PEI & $1.27[121]$ & & & 217 [121] & & $340-380$ [118] \\
\hline Nylon & 1.15 [122] & & & & $190-350$ [122] & 240-270 [118] \\
\hline HIPS & & & & & & $220-250[118]$ \\
\hline Polyester & $1.2-1.5$ [123] & & $40-90[123]$ & & & \\
\hline Vinyl ester & $1.12-1.32$ [123] & & $73-81$ [123] & & & \\
\hline
\end{tabular}

Composite is a category of material that is composed of more than one constituent combined to produce improved or altered properties that are not attainable in the separate 
constituent materials. For example, by combining a metal with other metals or non-metals, it may be possible to produce a targeted material that is hard and ductile [124]. Pure thermoplastics have low strength and stiffness and cannot retain their original shape at high temperatures to meet specific functional requirements; hence, they are replaced with their composite blends [118]. Various types of composites, such as those in the form of particulate, continuous and discontinuous fiber reinforcements, and nanocomposites were utilized to fabricate multi-material structures [53,125-127]. To fabricate particulate composite filaments for 3D printing, reinforcement particles are infused into a base polymer (matrix) and then processed into extruded filaments. The properties of the final material are dependent on particle size, shape, orientation, volume fraction and the interfaces between these particles and the matrix. Natural or synthetic fibers (e.g., glass, rice husk and carbon) are alternative reinforcements available for strengthening polymer matrices. The functional properties of the reinforced composite depend on the type of fibers and matrix used, fiber volume fraction, fiber alignment, the interfacial bond between the constituent materials and the void content [119]. Recently, Christ et al. investigated multi-material, bidirectional strain sensors that were fabricated using the FFF process [128]. Thermoplastic polyurethane (TPU) and multi-walled carbon nanotubes (MWCNT) were used. The 3D printer used for research offered two independent extrusion nozzles, which allowed for the use of two independent materials during printing. One nozzle deposited the pure TPU filament, while the second deposited the TPU/MWCNT filament. The printed sensors showed a strong piezoresistive response and good cyclic repeatability for both electrical and mechanical performance. In another study, Enrique et al. discussed the influence of micromechanical aspects such as fiber orientation, fiber distribution, the orientation distribution of fillers, waviness, and agglomeration on the post-buckling behavior of uniaxially compressed FGCNTRC (functionally graded carbon nanotube-reinforced composites) curved panels. It was found that both the axial and bending stiffness of the fabricated parts were enhanced with the increase in the CNT volume fraction [129].

\subsection{Metal-Ceramic Materials}

Ceramics are used in the chemical industry, machinery, electronics, aerospace and biomedical engineering because of their functional properties, i.e., their high mechanical strength and hardness, good thermal and chemical stability, and viable thermal, optical, electrical and magnetic performance $[107,130]$. Ceramics were extensively used along with metals to fabricate multi-material structures using AM technologies. Joining metal-ceramic materials is a relatively difficult process due to the different thermal-chemical properties of both material types. This is because the melting point of ceramic materials is higher than metals [131-133]. On the other hand, ceramic materials have been incorporated into a metal matrix to enhance the thermal properties, wear resistance, hardness and mechanical strength of the final composite structure [134-136].

Recently Zhang et al. proposed a multi-ceramic device providing both mechanical strength (niobium oxide and titanium dioxide-doped alumina) and electrical conductivity (alumina-doped zinc oxide) [137]. Gheisari et al. described the direct 3D printing of low temperature co-fired ceramics and floating electrode 3D structures. Slurry-based AM and selective laser burnout (SLB) were used to fabricate bulk dielectric, Bi2Mo2O9 with silver (Ag) internal floating electrodes [138]. In another study, Mitun et al. combined metalceramic parts through AM processes to create metallic structures with high-performance coatings such as silicon carbide composite coatings onto Ti6Al4V [139].

\subsection{Metals and Alloys}

Manufacturing multi-metal components using AM techniques has gained much attention amongst researchers. The most used metals in MMAM are titanium, stainless steel, aluminum, nickel and copper. Heer et al. fabricated compositionally graded magneticnonmagnetic bimetallic structures using a LENS system. A graded magnetic functionality was implemented by directly transitioning from non-magnetic austenitic stainless steel 
316 (SS316) to magnetic ferritic stainless steel 430 (SS430) in a single structure [140]. Yusuf et al. investigated the interfacial region of multi-material 316L stainless steel/Inconel 718 (316L SS/IN718) fabricated by laser powder bed fusion (L-PBF) [141]. The interfacial region was characterized by extensive scanning electron microscope (SEM) and electron backscattered diffraction (EBSD) observations, porosity analysis, and Vickers hardness testing. The IN 718 region exhibited the highest hardness, compared to the FZ and 316L SS regions. Tan investigated the effect of the elemental composition of materials on the interfacial bond strength through the laser powder bed fusion (LPBF) of two-type iron-based multi-materials, i.e., the AISI 304 stainless steel (SS304) and AISI 1045 carbon steel (CS 45). Mechanical performance was evaluated by static tensile and flexural tests and dynamic tension fatigue testing. The results reveal that the interfacial bond strength exceeds the fracture strength of substrate materials [142]. Sing et al. investigated the multi-material processing of AlSi10Mg and UNS C18400 carried out by SLM. The interfacial characteristics of $\mathrm{Al} / \mathrm{Cu}$ bimetallic laminates had been characterized. The bimetallic $\mathrm{Al} / \mathrm{Cu}$ laminates exhibited a higher tensile strength than that of copper but lesser than that of $\mathrm{AlSi} 10 \mathrm{Mg}$, and the bending test results concluded there is good bonding strength between AlSi10Mg and C18400 [143]. Demir et al. proposed his work on multi-material SLM platform and demonstrated its use for producing Fe/Al-12Si multi-material structures. The layers of $\mathrm{Fe} / \mathrm{Al}-12 \mathrm{Si}$ showed large cracks due to the low compatibility and miscibility of these two materials, whilst the obtained Fe/Al-12Si layers has the advantage of high hardness [144]. In another study, Singh et al. attempted to develop an $\mathrm{Al} / \mathrm{Al}_{2} \mathrm{O}_{3}$ composite as an FGM by using a reinforced FDM pattern in the investment casting (IC) process [145]. Similarly, Tan et al. fabricated a W-Cu (tungsten-copper) FGM firstly by SLM. The effects of the laser parameter on the interfacial defects, microstructure and bonding strength were discussed. It was observed that irregular-shaped pores and cracks were the main defects at the interface due to the intrinsic properties of materials [146]. Table 4 shows the various metals used in MMAM processes.

Table 4. Materials and their mechanical properties used in MMAM.

\begin{tabular}{|c|c|c|c|}
\hline Material & AM Technology & $\begin{array}{l}\text { Yield Strength } \\
\mathrm{MPa}\end{array}$ & $\begin{array}{l}\text { Hardness } \\
\text { HV }\end{array}$ \\
\hline Ti6Al4V/TiC (From 0\% to 50\% Ti [147] & LMD & & $380-737$ \\
\hline TA15/TiC (From $0 \%$ to $50 \% \mathrm{TiC}$ ) [148] & LMD & $806-925$ & \\
\hline Ti6Al4V / TiC (From 0\% to 30\% Ti) [149] & DED & & $300-600$ \\
\hline Ti6Al4V/SS304 L/V [150] & DED & & $220-850$ \\
\hline $\begin{array}{l}\text { TiAl4V / Invar (From Ti6Al4V to pure Invar with 3\% increment) } \\
\text { [151] }\end{array}$ & DED & & $350-858$ \\
\hline $\begin{array}{l}\text { Ti6Al4V / Mo (From Ti6Al4V to pure Mo with 25\% increment) } \\
\text { [152] }\end{array}$ & DED & & $250-450$ \\
\hline $\mathrm{Ti} 6 \mathrm{Al} 4 \mathrm{~V} / \mathrm{Al}_{2} \mathrm{O}_{3}[153]$ & LENS & & $350-2365$ \\
\hline SS AISI316L [154] & SLM & & $150-220$ \\
\hline SS 316L/Stellite12 with few millimeter transition zone [155] & LDM & & $200-650$ \\
\hline SS 316L/P21 with 25/50/75\% graded layers [156] & DED & & $200-440$ \\
\hline SS 316L/P21 + 316L SS/P21 [123] & DED & & $210-330$ \\
\hline SS430 + SS316 [140] & LENS & & $266 \pm 4,-174 \pm 3$ \\
\hline $\mathrm{AlSi} 10 \mathrm{Mg}+\mathrm{C} 18400[143]$ & SLM & & $119.06 \pm 9.1,-71 \pm 7.45$ \\
\hline 316L SS + IN 718 [141] & L-PBF & & 304,223 \\
\hline CS 45 and CS/MS [142] & L-PBF & $562 \pm 22,596$ & \\
\hline SS $304[142]$ & L-PBF & $514 \pm 16$ & \\
\hline $\mathrm{Fe} / \mathrm{Al}-12 \mathrm{Si}[144]$ & SLM & & $450-550$ \\
\hline
\end{tabular}

\section{Applications of MMAM}

Through MMAM, single- and multi-functional structures are built to meet requirements for complexity and improved performance for applications in industries that include aerospace, soft robotics, medical, electronics, automotive and food processing [39,102,144].

Within the aerospace industry, MMAM is used to achieve complex shapes and processing techniques that are not possible when using conventional methods. Electric motors and turbine engines with integrated sub-elements of different materials and structures 
are examples of components that are built with the aid of MMAM to attain unique and superior properties (e.g., microstructure, mechanical, electrical, thermal and magnetic) [52]. Laser-based powder bed fusion is one of the AM processes that can be used or combined with another AM process to build metallic and non-metallic materials (e.g., metal-metal, metal-ceramic, and metal-polymer components) with high geometrical resolution [38].

Soft robots are inherently compliant and exhibit large strains in normal operation compared to conventionally rigid robots [157]. As suggested by their name, they are elastically soft and capable of safely cooperating with humans or steering through constrained environments [158]. Soft robotic systems in MMAM are now popular by virtue of improved materials, and AM processes offer the possibility of directly fabricating mainly elastomeric components to mimic complex motions such as jumping, movements, gripping and releasing [159]. The manufacturing process mainly comprises the direct printing of smart materials and molds for soft robotics that are suitable for medical and other industrial applications [158].

In biomedical engineering, MMAM has proven to be relevant in the design and manufacturing of hand orthoses using PLA and TPU with comparable results to conventional plaster casts [160]. In dental technology, support structures of castable multi-material denture frameworks built by material jetting process can be melted away easily in a heated oven [5]. Similarly, polymeric end-use devices do not require harsh postprocessing like counterparts fabricated with vat-photopolymerization [5]. Medical models for training and educational purposes (Figure 15b) exhibit unique and real-life appearances in terms of color and material transitions when built with MMAM [161].

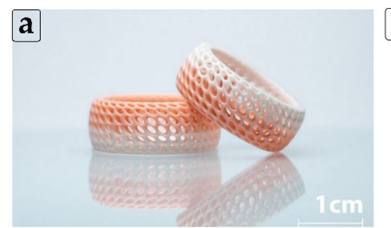

b
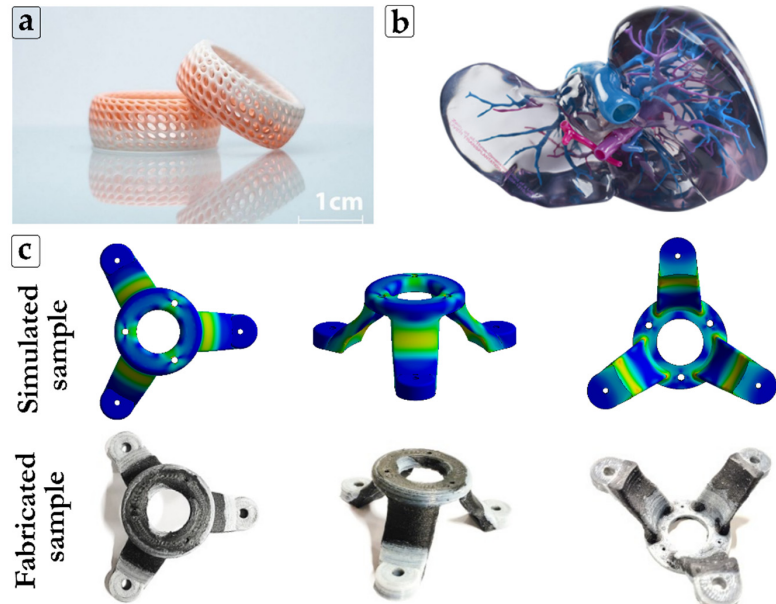

Top view
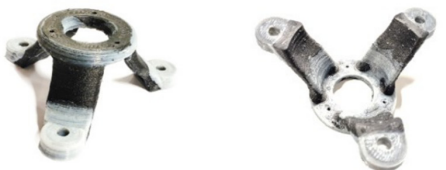

Isometric view

Bottom view

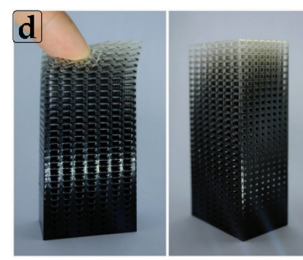

e

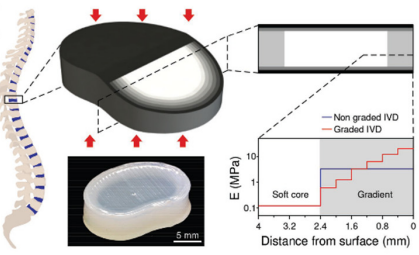

Figure 15. (a) Multi-material ceramics 3D printing using CeraFab Multi 2M30 printer, reproduced with permission, photo by Lithoz GmbH, Copyright (C) 2021 [162], (b) 3D-printed medical model for educational purposes [163], (c) optimized material distribution of short carbon fiber reinforcements in the ABS matrix; mounting bracket part was fabricated by the FFF technology [101], (d) multi-material functionally graded lattice structure produced on the Stratasys J750 with GradCAD Voxel Print, reproduced with permission [164], (e) illustration of the loading condition as well as the gradient design of the printed human intervertebral disk. Reproduced with permission, Copyright (C) 2018 [78]. 
Other unique applications include the possibility to print dual-functional scaffolds through the direct incorporation of antibiotics [165] and dental resins with antibacterial monomers to prevent the formation of secondary caries [166].

In general, multi-material systems form essential aspects of 3D bioprinting for tissue engineering and regeneration, including the precise layering of cells, biologic scaffolds and biologic factors with the goal of recapitulating biologic tissue [167] and associated innovative research [168]; pharmaceutical development of customized pills [169]; 4D printing of structures or pre-programmed 'smart materials' to assume different shapes and forms when subjected to different stimuli such as a magnetic field, ultrasound, light, temperature, water, $\mathrm{pH}$, mechanical and solvent [170,171]; 3D electronic devices of dissimilar materials [106]; metal material extrusion [59]; and fiber-reinforced composites [55,57].

\section{Critical Issues and Challenges Associated with MMAM}

MMAM is the process of joining materials with different thermo-mechanical properties to enhance the overall performance of the entire structure. There are limitations of this process, whether it combines multiple polymers, metals or metal and ceramics. Another material- and process-related limitation may relate to real-world applications such as dimensional accuracy and size, the need for post processing, the lack of processability to combine different materials at the same time under the same environment, etc. MMAM has been explored in recent years with a variety of processes and methods, but the majority still tends to produce multiple material structures by assigning materials to different layers. This approach experiences issues associated with the difficulty of bonding dissimilar materials.

Several research investigations addressed the strength of multi-material interfaces. Lumpe et al. conducted a study on the tensile properties of multi-material interfaces manufactured by material jetting processes [172]. In this study, it was found that interfaces had strong dependencies on material combination and print orientation. Rigid and compliant material interfaces were mostly found to be strong as compared to the soft material itself. In another study, rigid-soft material combinations were applied for robotic applications [173]. The elastic modulus of the multi-material part was varied from $1 \mathrm{MPa}$ to $1 \mathrm{GPa}$, which allowed it to soften external impacts while maintaining a semi-rigid overall shape and survive longer than its purely rigid or flexible counterparts. $\mathrm{Vu}$ et al. performed the interface characterization of soft (TB) and stiffer (VW) material combinations using several test methods. The authors found that fracture failures nominally occurred at the interface zones [67]. They performed a T-peel test, which demonstrated that the gradient pattern yielded much better peel resistance than the direct transition interface $(62 \%$ higher in terms of both average peel force and energy release rate). Mirzaali et al. [12] investigated the fracture behavior of bio-inspired functionally graded rigid-soft composites with the help of a material jetting technique. It was found that the fracture properties of multi-material gradient specimens were significantly influenced by the longer transition zone.

Lately, researchers have investigated the efficient use of multi-material parts using a gradient approach $[9,90,102,174,175]$. These structures with graded regions of varying materials can be built in a continuous way using a single AM machine that combines various steps and eventually reduces the manufacturing time and cost. MMAM is a revolutionary approach, and a broad range of implementations can also generate new opportunities in the fabrication of advanced FGMs as structural materials with new forms of functionalities and properties in aerospace, automobile and medical industries [68,176]. The effect of influencing factors of AM processes on the strength of interfaces was investigated. Freund et al. [177] conducted a research study to find the effect of factors on the interface strength of AM-made components. Ezair et al. [178] developed a software interface that allows designers to volumetrically apply material choices to their designs. Within this framework, the authors fabricated multi-material structures that demonstrated the control of porous regions and the deposition of differing materials with repeatable patterns. Similarly, $\mathrm{Vu}$ et al. $[67,68]$ investigated the interface characteristics of soft (TangoBlackPlus, TB) and stiffer (VeroWhitePlus, VW) material combinations using various test methods. The study 
revealed that the fracture failures nominally occurred at the interface zones. The T-peel test also showed that the gradient pattern at the boundary region yielded much better peel resistance than the direct transition interface $(62 \%$ higher in terms of both average peel force and energy release rate). Lately, Kuipers et al. performed a new approach to design interfaces with an interlaced topologically interlocking lattice (ITIL) approach [179] as shown in Figure 16A-C. In this approach 3D lattice consisting of interlaced horizontal beams were created at the interface region by vertically aligning them so that they were topologically interlocked. The results show that the ITIL design satisfied the extrusion continuity constraint, which led to improvement in the ultimate tensile strength of the interfaces. Moreover, Stoner et al. designed a multi-material interface mesostructure with triply periodic minimal surface design patterns (Figure 16D) to improve the joint region [180]. In other work, Hasanov et al. investigated the gradient interface strength with respect to direct and interlocked pattern [9] as shown in Figure 16E,F. According to the study, joining process occurs at the layer-to-layer contact area of two materials. It is evident that the strength of joining process depends on the intermolecular diffusion quality between PC and ABS polymer chains (Figure 16H).
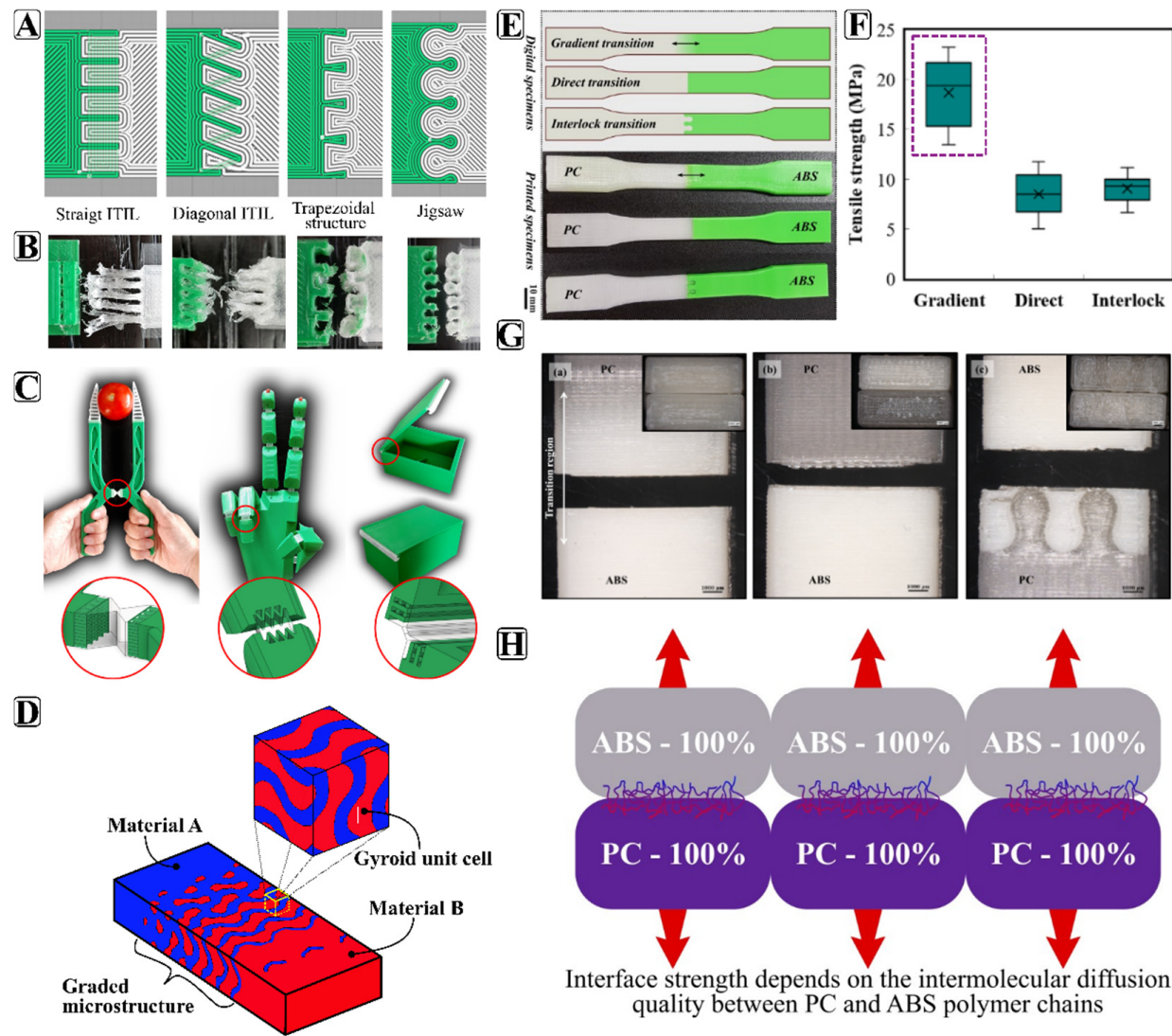

G

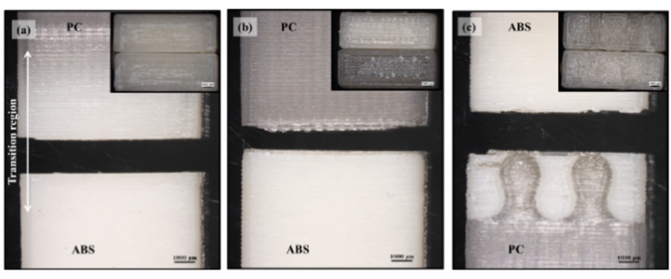

H

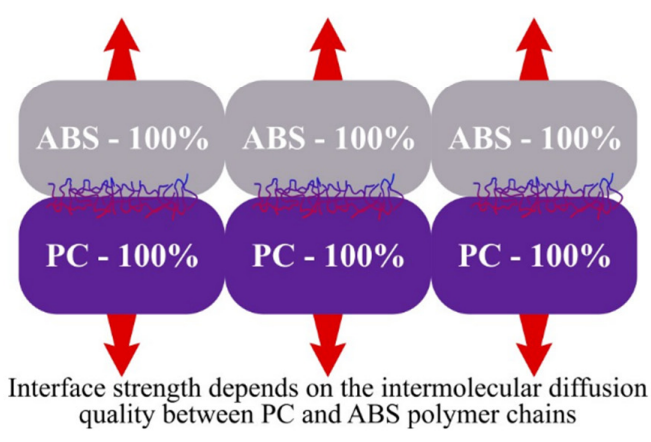

Figure 16. Various interface design strategies: (A) Gcodes generated with Cura Arachne engine beta. The straight and diagonal ITIL lattices produce continuous extrusion beads; the toolpaths for the dovetail designs include small, separated segments, (B) broken samples after tensile test, (C) various applications of dual-material parts using the ITIL approach and A gripper making use of the straight ITIL variant. A prosthetic hand using the diagonal ITIL variant. A storage box utilizing the straight ITIL variant. Images $(\mathbf{A}-\mathbf{C})$ were reprinted for free with no permission required under http:/ / creativecommons.org/licenses/by/4.0/ through article (accessed on 20 November 2021) [179], (D) bicontinuous mesostructural geometry with compositional gradation in material extrusion [180], (E) designed interface patterns using voxelization method and fabricated by the FFF process, (F) gradient test sample showing higher interface strength, $(G)$ fractured specimens, $(\mathrm{H})$ direct interface of fused filament fabrication-made multi-material part that has a direct transition from ABS to polycarbonate (PC) material. Red arrows indicate the tension (loading) direction. 
Another research study relating to interface design was conducted by Guessasma et al. [11]. The Authors investigated the tensile properties of the interfaces between two dissimilar polymers (ABS and TPU) printed using the droplet-based AM process. In this research, porosity analysis was performed using a 3D imaging technique. It was found that the pore connectivity inside the components was surprisingly low compared to the filament-based extrusion processes.

Apart from interface issues, one must consider the material selection, design and manufacturing aspects of MMAM issues. The main challenge is to select appropriate materials, understanding the composition and optimal distribution of materials inside the fabricated parts [63]. Since mixing materials with variable and non-uniform properties are complex, background information related to material characteristics, properties, chemical composition, and manufacturing constraints are necessary prior to processing these materials [181-183]. Therefore, specific databases should be established to identify the list of relative materials that can be processed under the same conditions.

As discussed previously, interface issues emerge when joining dissimilar materials in MMAM. To overcome high stress concentrations at the material transition zone, a gradual change in materials has been extensively investigated in the literature [101]. However, investigation on the microstructural formation and chemical composition must be carefully measured and quantified. Most of the research studies were focused on the processability of various materials using different AM methods. There is a need to investigate the effect of transition length and gradient composition. The characterization of thermo-mechanical properties of the interface zone is still unclear, and more research must be carried out in this direction [183].

Overall, several research studies have investigated the interface characteristics of AMmade parts that consisted of different material combinations. Table 5 shows the literature review of multi-material AM research studies based on methods used to fabricate multimaterial parts and the properties that were investigated. Based on the literature reviews, most of the research investigations were conducted on the interface characterization of rigid-soft material combinations with the help of the material jetting process. In general, according to the reviewed literature, there are challenges in the successful fabrication of multi-material components using MMAM technologies. These are design-, material- and process-related issues. One design-related concern is the development of CAD programs that enable the user to design gradient material interfaces in MMAM. In this context, specific design protocols and procedures need to be developed. One material-related challenge is the compatibility issue, especially between dissimilar materials, which creates weak interface bonds. Another issue could be the contamination between materials during the nozzle changing process. Contamination makes the processes imperfect and the reuse of materials difficult. As a result, MMAM has the potential to become an important resource for the next generation of manufacturing technologies.

Table 5. Literature review of multi-material AM research studies.

\begin{tabular}{ccc}
\hline Authors/Reference & Methods (AM Technique) & Investigated Properties \\
\hline $\begin{array}{c}\text { Garland et al. [28] } \\
\text { Hasanov et al. }\end{array}$ & Bi-level topology optimization (FFF) & $\begin{array}{c}\text { Flexural behavior, } \\
\text { [9,101,102] }\end{array}$ \\
Brischetto et al. [29] & $\begin{array}{c}\text { External layer ABS, while internal layer with PLA } \\
\text { sandwich structure (FFF) }\end{array}$ & $\begin{array}{c}\text { Optimization of material distribution } \\
\text { Numerical and experimental investigation of FGM } \\
\text { parts }\end{array}$ \\
Lopez et al. [30] & Tensile specimen of sandwich structures (FFF) & $\begin{array}{c}\text { Tensile behavior of various material combinations } \\
\text { of sandwich structures } \\
\text { Tensile behavior }\end{array}$ \\
Kim et al. [184] & Tensile test (FFF) & Bending properties \\
Roger et al. [185] & Topology Optimization (TO), FEA (FFF) & $\begin{array}{c}\text { Selectively material placement based on FEA } \\
\text { results }\end{array}$ \\
\hline
\end{tabular}


Table 5. Cont.

\begin{tabular}{|c|c|c|}
\hline Authors/Reference & Methods (AM Technique) & Investigated Properties \\
\hline Singh et al. [145] & Tensile tests (FFF) & $\begin{array}{l}\text { Tensile behavior of specimens with different } \\
\text { printing speed and infill density }\end{array}$ \\
\hline Sudbury et al. [175] & $\begin{array}{c}\text { Development of BAAM system for FGM } \\
\text { fabrication (BAAM) }\end{array}$ & Cost, weight analysis \\
\hline Bracket et al. [186] & $\begin{array}{l}\text { Repeatability of mixing and printing process } \\
\text { (BAAM) }\end{array}$ & Fabrication of FGM sandwich structure \\
\hline Zheng et al. [6] & $\begin{array}{l}\text { Compression test, Dynamic Material Analysis } \\
\text { (SLA) }\end{array}$ & Energy dissipation characterizations, damping \\
\hline Ituarte et al. [27] & Tensile test, FEA, TO (MJ) & Tensile behavior \\
\hline Dorcas et al. [26] & Tensile test (MJ) & Tensile behavior \\
\hline Doubrovski et al. [24] & Voxel-based design, bitmap printing (MJ) & $\begin{array}{c}\text { Generation of FGM distribution on prosthetic } \\
\text { socket }\end{array}$ \\
\hline Freund et al. [177] & Peel test, plasma treatment (FFF) & Peel resistance \\
\hline Lopes et a. [187] & Tensile test (FFF) & Interface strength of zebra-like patterns \\
\hline Guessasma et al. [11] & Tensile test, DIC (BJ) & $\begin{array}{c}\text { Strength of different interface patterns, porosity } \\
\text { analysis using CT scan }\end{array}$ \\
\hline Vu et al. [68] & Interface characterization, tension test (MJ) & Fracture resistance \\
\hline Bartlett et al. [173] & FEA simulation, experiments (MJ) & $\begin{array}{c}\text { Fabrication of robotic rigid-flex legs for jumping } \\
\text { applications }\end{array}$ \\
\hline Lumpe et al. [172] & Tensile test (MJ) & Tensile properties of interfaces \\
\hline Mueller et al. [188] & Hardness test (MJ) & $\begin{array}{l}\text { Stiffness properties of various concentrations of } \\
\text { rigid-soft composites }\end{array}$ \\
\hline Mirzaali et al. [12] & Tensile test (MJ) & Fracture resistance properties \\
\hline
\end{tabular}

As discussed before, there much effort is still needed to be before multiple materials can be incorporated in AM commercially. Below, the common challenges and technological barriers that need to be addressed in MMAM processes are given.

\section{Future Trends}

MMAM has significant potential that can be explored to expand the scope of current applications as it continues to gain popularity. Among the various AM processes, HAM combined with prefabricated parts in a 3D printer could potentially manufacture dimensionally accurate smart systems in a continuous single process. MMAM is capable of making parts that were previously unheard of. It allows for adaptable designs to be made as well as materials with superior properties in comparison with traditional manufacturing methods. AM technologies allow materials to be joined to form composites, change their thermo-mechanical properties, or create new materials completely. The future of this technology will advance the use of polymers for functional materials, fiber-reinforced composites, metal-matrix composites, and metal-ceramic composites.

$3 \mathrm{D}$ printing is suitable for manufacturing various smart structures because of its multi-material compatibility and capacity for personalized customization and integrated fabrication. Although the 3D printing of multi-material parts promises useful applications in the future, there are certain issues that need to be addressed. There are a wide range of functional materials with excellent properties that are not printable because they have unsuitable thermal and rheological properties. Moreover, several enhanced AM methods have been proposed, but effective methods for many materials remain lacking, so this would be an immensely beneficial aim of future work or research directions.

\subsection{Improving Software Capabilities}

Improving software capabilities to design highly complex FGM patterns is necessary, as the use of traditional design methodologies limits the ability to exploit the full capabilities of FGAM creatively and intuitively. More control of gradient transition direction and transition length is an essential step in modeling FGM designs. Current commercial slicers are limited to slicing and exporting FGMs to fabricate using FFF technology. Although there 
have been some attempts to design multi-material components with gradient regions, most of them use in-house computer codes [28,62,189], and defining locally varying material properties on CAD models is a tedious and time-consuming process. There is a need for future developments in the design of computer programs to define material properties interactively and intuitively at specified regions of the components with various directions.

\subsection{Thermo-Mechanical Characterization of Material Interfaces}

The defects and interface bonding strength of 3D-printed structures significantly reduce their strength and durability. Since multi-material parts have a wide range of potential application areas, there is a need to produce reliable components with stronger interface joints. Additionally, the interface can also be affected by various temperature conditions, and multi-material parts can be used for energy conversion devices and other energy-related applications. Multi-material parts can effectively provide a thermal barrier and can be used as a protective coating in specific applications. Although there have been some research studies performed to characterize the mechanical strength of the interfaces, the characterization of thermal properties at material joints is an essential step for designing multi-functional products with improved thermo-mechanical properties.

\subsection{Incorporating Big Area Additive Manufacturing (BAAM) into MMAM}

The large-scale manufacturing process would allow the fabrication of functional parts for aerospace, construction and some other fields. Since material cost and weight are important design considerations, it is very important to fabricate multi-material parts with site-specific material allocation. According to a recent study performed in the Oak Ridge National Lab (ORNL), the fabrication of a sandwich plate with a gradient material core would reduce the weight up to $5 \%$ and cut the expense by roughly $45 \%$ of the previous cost [175]. In addition, multi-material structures remain in the demonstration stage with no specific application scenario. Although there were some attempts to characterize material transition using BAAM technology, its full capability in the fabrication of large-scale components is still in its infancy. Accordingly, further research on this field is necessary.

\subsection{New Extruder Designs for Better Material Mixing for ME Process}

One of the limiting factors is the need for high precision and accuracy in the material composition during fabrication process. This is especially needed for FFF techniques. FFF is a low-cost technique that is gaining attention among designers, researchers, and engineers. However, the material mixing capability of this technology limits its potential. In this context, the design of a nozzle geometry and mixing chamber with an effective mixing method could be investigated. Since the consistent and uniform mixing of two materials is highly dependent on the nozzle geometry and design of the mixing chamber, computational fluid dynamic methods could be applied for new nozzle design possibilities. In addition, depositing FGMs using dynamic mixers could also be investigated, especially for BAAM, to improve the uniformity of the material mixing.

\section{Conclusions}

In this review paper, the latest developments, challenges, and future potential of MMAM are summarized for various types of materials and their potential applications ranging from electronics, biomedical field, tissue engineering and soft robotics. The paper also outlines the challenges and outlook based on the current applications of the MMAM process. Future improvement of printing hardware, materials and the accurate prediction of interface properties based on numerical and theoretical analysis will widen the use and applications of MMAM. Despite the current challenges, it is evident that the field of AM and, more specifically, AM applied to multi-material fabrication, offers immense potential.

Author Contributions: Conceptualization, S.H., A.G., I.F., F.A.-S.; methodology, S.H., A.G., S.A., M.R., I.F., F.A.-S.; investigation, writing-original draft preparation, S.H., S.A., M.R., I.F., F.A.-S.; writing-review and editing, S.H., S.A., M.R., I.F., F.A.-S., O.H., A.R.; visualization, S.H.; supervision, 
I.F., A.G., F.A.-S.; project administration, I.F.; funding acquisition, I.F. All authors have read and agreed to the published version of the manuscript.

Funding: This research received no external funding.

Data Availability Statement: The specifics of the literature review data can be provided upon request.

Acknowledgments: The support provided by the team of the Additive Manufacturing Research and Innovation Laboratory located at Tennessee Tech University is acknowledged.

Conflicts of Interest: The authors declare no conflict of interest.

\section{References}

1. Fidan, I.; Imeri, A.; Gupta, A.; Hasanov, S.; Nasirov, A.; Elliott, A.; Alifui-Segbaya, F.; Nanami, N. The trends and challenges of fiber reinforced additive manufacturing. Int. J. Adv. Manuf. Technol. 2019, 102, 1801-1818. [CrossRef]

2. Joshi, S.C.; Sheikh, A.A. 3D printing in aerospace and its long-term sustainability. Virtual Phys. Prototyp. 2015, 10, 175-185. [CrossRef]

3. Buchanan, C.; Matilainen, V.P.; Salminen, A.; Gardner, L. Structural performance of additive manufactured metallic material and cross-sections. J. Constr. Steel Res. 2017, 136, 35-48. [CrossRef]

4. Ford, S.L.N. Additive Manufacturing Technology: Potential Implications for US Manufacturing Competitiveness. J. Int'l Com. Econ. 2014, 6, 40.

5. Alifui-Segbaya, F. Biomedical photopolymers in 3D printing. Rapid Prototyp. J. 2019, 26, 437-444. [CrossRef]

6. Xu, Z.; Ha, C.S.; Kadam, R.; Lindahl, J.; Kim, S.; Wu, H.F.; Kunc, V.; Zheng, X. Additive manufacturing of two-phase lightweight, stiff and high damping carbon fiber reinforced polymer microlattices. Addit. Manuf. 2020, 32, 101106. [CrossRef]

7. Alifui-Segbaya, F.; Bowman, J.; White, A.R.; George, R.; Fidan, I.; Love, R.M. Chemical characterization of additively manufactured methacrylates for dental devices. Addit. Manuf. 2020, 31, 100944. [CrossRef]

8. Singh, R.; Kumar, R.; Farina, I.; Colangelo, F.; Feo, L.; Fraternali, F. Multi-material additive manufacturing of sustainable innovative materials and structures. Polymers 2019, 11, 62. [CrossRef]

9. Hasanov, S.; Gupta, A.; Nasirov, A.; Fidan, I. Mechanical characterization of functionally graded materials produced by the fused filament fabrication process. J. Manuf. Process. 2020, 58, 923-935. [CrossRef]

10. Putra, N.E.; Mirzaali, M.J.; Apachitei, I.; Zhou, J.; Zadpoor, A.A. Multi-material additive manufacturing technologies for Ti-, Mg-, and Fe-based biomaterials for bone substitution. Acta Biomater. 2020, 109, 1-20. [CrossRef]

11. Guessasma, S.; Nouri, H.; Roger, F. Microstructural and mechanical implications of microscaled assembly in droplet-based multi-material additive manufacturing. Polymers 2017, 9, 372. [CrossRef]

12. Mirzaali, M.J.; de la Nava, A.H.; Gunashekar, D.; Nouri-Goushki, M.; Doubrovski, E.L.; Zadpoor, A.A. Fracture behavior of bio-inspired functionally graded soft-hard composites made by multi-material 3D printing: The case of colinear cracks. Materials 2019, 12, 2735. [CrossRef]

13. Sheydaeian, E. Systems, Materials, and Methodologies for Multi-Material Hybrid Additive Manufacturing Functionally Graded Structures. Ph.D. Thesis, University of Waterloo, Waterloo, ON, Canada, October 2017.

14. Vaezi, M.; Chianrabutra, S.; Mellor, B.; Yang, S. Multiple material additive manufacturing - Part 1: A review: This review paper covers a decade of research on multiple material additive manufacturing technologies which can produce complex geometry parts with different materials. Virtual Phys. Prototyp. 2013, 8, 19-50. [CrossRef]

15. Toursangsaraki, M. A Review of Multi-Material and Composite Parts Production by Modified Additive Manufacturing Methods. arXiv 2018, arXiv:1808.01861.

16. Li, Y.; Feng, Z.; Hao, L.; Huang, L.; Xin, C.; Wang, Y.; Bilotti, E.; Essa, K.; Zhang, H.; Li, Z.; et al. A Review on Functionally Graded Materials and Structures via Additive Manufacturing: From Multi-Scale Design to Versatile Functional Properties. Adv. Mater. Technol. 2020, 5, 1900981. [CrossRef]

17. Ahankari, S.S.; Kar, K.K. Functionally graded composites: Processing and applications. In Composite Materials: Processing, Applications, Characterizations; Springer: Berlin/Heidelberg, Germany, 2016; pp. 119-168. ISBN 9783662495148.

18. Kieback, B.; Neubrand, A.; Riedel, H. Processing techniques for functionally graded materials. Mater. Sci. Eng. A 2003, 362, 81-106. [CrossRef]

19. Chung, H.; Das, S. Processing and properties of glass bead particulate-filled functionally graded Nylon-11 composites produced by selective laser sintering. Mater. Sci. Eng. A 2006, 437, 226-234. [CrossRef]

20. Ahsan, M.R.U.; Tanvir, A.N.M.; Ross, T.; Elsawy, A.; Oh, M.S.; Kim, D.B. Fabrication of bimetallic additively manufactured structure (BAMS) of low carbon steel and 316L austenitic stainless steel with wire + arc additive manufacturing. Rapid Prototyp. J. 2019, 26, 519-530. [CrossRef]

21. Ahsan, M.R.U.; Tanvir, A.N.M.; Seo, G.J.; Bates, B.; Hawkins, W.; Lee, C.; Liaw, P.K.; Noakes, M.; Nycz, A.; Kim, D.B. Heattreatment effects on a bimetallic additively-manufactured structure (BAMS) of the low-carbon steel and austenitic-stainless steel. Addit. Manuf. 2020, 32, 101036. [CrossRef]

22. Mahamood, R.M.; Akinlabi, E.T. Laser metal deposition of functionally graded Ti6A14V/TiC. Mater. Des. 2015, 84, 402-410. [CrossRef] 
23. Jeong, J.-S.; Shin, K.-H. Fabrication of Functionally Graded Materials Between P21 Tool Steel and Cu by Using Laser-Aided Layered Manufacturing. Trans. Korean Soc. Mech. Eng. A 2013, 37, 61-66. [CrossRef]

24. Doubrovski, E.L.; Tsai, E.Y.; Dikovsky, D.; Geraedts, J.M.P.; Herr, H.; Oxman, N. Voxel-based fabrication through material property mapping: A design method for bitmap printing. CAD Comput. Aided Des. 2015, 60, 3-13. [CrossRef]

25. Skylar-Scott, M.A.; Mueller, J.; Visser, C.W.; Lewis, J.A. Voxelated soft matter via multimaterial multinozzle 3D printing. Nature 2019, 575, 330-335. [CrossRef]

26. Kaweesa, D.V.; Meisel, N.A. Material Property Changes in Custom-Designed Digital Composite Structures Due to Voxel Size. In Proceedings of the 29th Annual International Solid Freeform Fabrication Symposium-An Additive Manufacturing Conference, Austin, TX, USA, 13-15 August 2018; pp. 1499-1510.

27. Ituarte, I.F.; Boddeti, N.; Hassani, V.; Dunn, M.L.; Rosen, D.W. Design and additive manufacture of functionally graded structures based on digital materials. Addit. Manuf. 2019, 30, 100839. [CrossRef]

28. Garland, A.; Fadel, G. Design and Manufacturing Functionally Gradient Material Objects with an off the Shelf Three-Dimensional Printer: Challenges and Solutions. J. Mech. Des. Trans. ASME 2015, 137, 111407. [CrossRef]

29. Brischetto, S.; Ferro, C.G.; Torre, R.; Maggiore, P. 3D FDM production and mechanical behavior of polymeric sandwich specimens embedding classical and honeycomb cores. Curved Layer. Struct. 2018, 5, 80-94. [CrossRef]

30. Lopez, D.M.B.; Ahmad, R. Tensile mechanical behaviour of multi-polymer sandwich structures via fused deposition modelling Polymers 2020, 12, 651. [CrossRef]

31. Chueh, Y.-H.; Zhang, X.; Wei, C.; Sun, Z.; Li, L. Additive Manufacturing of Polymer-Metal/Ceramic Functionally Graded Composite Components via Multiple Material Laser Powder Bed Fusion. J. Manuf. Sci. Eng. 2020, 142, 051003. [CrossRef]

32. Chueh, Y.H.; Wei, C.; Zhang, X.; Li, L. Integrated laser-based powder bed fusion and fused filament fabrication for threedimensional printing of hybrid metal/polymer objects. Addit. Manuf. 2020, 31, 100928. [CrossRef]

33. Richards, D.; Abram, T.; Rennie, A. Designing Digital Materials with Volumetric Gradients. In Proceedings of the 15th Rapid Design, Prototyping \& Manufacturing Conference (RDPM2017), Northumbria University, Newcastle, UK, $27-28$ April 2017.

34. Multi Material 3D Printing by Aerosint's Selective Powder Deposition. Available online: https://aerosint.com/how-to-makecheap-scalable-multi-material-3d-printing-a-reality/ (accessed on 5 November 2021).

35. ParaMatters I Technology. Available online: https://paramatters.com/technology/ (accessed on 5 November 2021).

36. Gallery of Synthesis Design + Architecture Utilizes Gradient 3-D Printing in "Durotaxis Chair". Available online: https:/ / www.archdaily.com/610939/synthesis-design-architecture-utilizes-gradient-3-d-printing-in-durotaxis-chair/55 0985aae58eceb0fa00003d-durotaxis_down_2-jpg?next_project=no (accessed on 17 November 2021).

37. Chen, D.; Zheng, X. Multi-material Additive Manufacturing of Metamaterials with Giant, Tailorable Negative Poisson's Ratios. Sci. Rep. 2018, 8, 9139. [CrossRef] [PubMed]

38. Wei, C.; Li, L. Recent progress and scientific challenges in multi-material additive manufacturing via laser-based powder bed fusion. Virtual Phys. Prototyp. 2021, 16, 347-371. [CrossRef]

39. Han, D.; Lee, H. Recent advances in multi-material additive manufacturing: Methods and applications. Curr. Opin. Chem. Eng. 2020, 28, 158-166. [CrossRef]

40. Chastel, Y.; Passemard, L. Joining Technologies for Future Automobile Multi-material Modules. Procedia Eng. 2014, 81, 2104-2110. [CrossRef]

41. Smithy Secrets: An Intro to Forging Methods I Metal Casting Resources. Available online: https://www.reliance-foundry.com/ blog/forging (accessed on 2 November 2021).

42. Black, J.T.; Kohser, R.A. DeGarmo's Materials and Processes in Manufacturing, 13th ed.; Black, J.T., Kohser, R.A., Eds.; Willey: Hoboken, NJ, USA, 2019; ISBN 978-1-119-49282-5.

43. Priyadarshi, A.K.; Gupta, S.K.; Gouker, R.; Krebs, F.; Shroeder, M.; Warth, S. Manufacturing multi-material articulated plastic products using in-mold assembly. Int. J. Adv. Manuf. Technol. 2007, 32, 350-365. [CrossRef]

44. Gouker, R.M.; Gupta, S.K.; Bruck, H.A.; Holzschuh, T. Manufacturing of multi-material compliant mechanisms using multimaterial molding. Int. J. Adv. Manuf. Technol. 2006, 30, 1049-1075. [CrossRef]

45. Meschut, G.; Hahn, O.; Janzen, V.; Olfermann, T. Innovative joining technologies for multi-material structures. Weld. World 2014, 58, 65-75. [CrossRef]

46. Friction Element Welding Innovations for Hybrid Body Parts Dr. Uwe Alber (AUDI AG) April, 19th 2012. Available online: https:/ / businessdocbox.com/Metals/70595739-Friction-element-welding-innovations-for-hybrid-body-parts-dr-uwealber-audi-ag-april-19-th-2012.html (accessed on 2 November 2021).

47. Wohletz, S.; Groche, P. Temperature Influence on Bond Formation in Multi-Material Joining by Forging. Procedia Eng. 2014, 81, 2000-2005. [CrossRef]

48. Behrens, B.-A.; Chugreev, A.; Matthias, T.; Poll, G.; Pape, F.; Coors, T.; Hassel, T.; Maier, H.J.; Mildebrath, M. Manufacturing and Evaluation of Multi-Material Axial-Bearing Washers by Tailored Forming. Metals 2019, 9, 232. [CrossRef]

49. Understanding The History of Machining Tools and Their Uses. Available online: https://thewerkscandc.com/understandingthe-history-of-machining-tools-and-their-uses / (accessed on 2 November 2021).

50. Fidan, I. Benchmarking Studies for 3D Printing Process. In Proceedings of the SME's First Annual Manufacturing Technology Summit, Dearborn, MI, USA, 4 May 2004. 
51. Numerical Control-Wikipedia. Available online: https://en.wikipedia.org/wiki/Numerical_control (accessed on 2 November 2021).

52. Halbig, M.C.; Singh, M.; Singh, M. Additive Manufacturing of Multi-Material Systems for Aerospace Applications. Available online: https:/ / ntrs.nasa.gov/ citations / 20190032205 (accessed on 2 November 2021).

53. Nasirov, A.; Hasanov, S.; Fidan, I.; Technology, E. Prediction of Mechanical Properties of Fused Deposition Modeling Made Parts using Multiscale Modeling and Classical Laminate Theory. In Proceedings of the 30th Annual International Solid Freeform Fabrication Symposium-An Additive Manufacturing Conference, Austin, TX, USA, 12-14 August 2019; pp. $1373-1382$.

54. Wickramasinghe, S.; Do, T.; Tran, P. FDM-Based 3D Printing of Polymer and Associated Composite: A Review on Mechanical Properties. Polymers 2020, 12, 1529. [CrossRef] [PubMed]

55. Gupta, A.; Fidan, I.; Hasanov, S.; Nasirov, A. Processing, mechanical characterization, and micrography of 3D-printed short carbon fiber reinforced polycarbonate polymer matrix composite material. Int. J. Adv. Manuf. Technol. 2020, 107, 3185-3205. [CrossRef]

56. Gupta, A.; Hasanov, S.; Fidan, I.; Zhang, Z. Homogenized modeling approach for effective property prediction of 3D-printed short fibers reinforced polymer matrix composite material. Int. J. Adv. Manuf. Technol. 2021, 1-18. [CrossRef]

57. Gupta, A.; Hasanov, S.; Fidan, I. Processing and characterization of 3d-printed polymer matrix composites reinforced with discontinuous fibers. In Proceedings of the 30th Annual International Solid Freeform Fabrication Symposium-An Additive Manufacturing Conference, Austin, TX, USA, 12-14 August 2019; pp. 1054-1066.

58. Hasanov, S.; Fidan, I. Additive Manufacturing of Magnetic Materials. MatEDU Resour. Cent. 2020. [CrossRef]

59. Mohammadizadeh, M.; Lu, H.; Fidan, I.; Tantawi, K.; Gupta, A.; Hasanov, S.; Zhang, Z.; Alifui-Segbaya, F.; Rennie, A. Mechanical and Thermal Analyses of Metal-PLA Components Fabricated by Metal Material Extrusion. Inventions 2020, 5, 44. [CrossRef]

60. Hasanov, S. Manufacturing of Soft Magnets using the Fused Filament Fabrication Process. MatEDU Resour. Cent. 2021, 1-13. [CrossRef]

61. Yin, J.; Lu, C.; Fu, J.; Huang, Y.; Zheng, Y. Interfacial bonding during multi-material fused deposition modeling (FDM) process due to inter-molecular diffusion. Mater. Des. 2018, 150, 104-112. [CrossRef]

62. Sanders, E.D.; Aguiló, M.A.; Paulino, G.H. Multi-material continuum topology optimization with arbitrary volume and mass constraints. Comput. Methods Appl. Mech. Eng. 2018, 340, 798-823. [CrossRef]

63. Khondoker, M.A.H.; Asad, A.; Sameoto, D. Printing with mechanically interlocked extrudates using a custom bi-extruder for fused deposition modelling. Rapid Prototyp. J. 2018, 24, 921-934. [CrossRef]

64. Kennedy, Z.C.; Christ, J.F. Printing polymer blends through in situ active mixing during fused filament fabrication. Addit. Manuf. 2020, 36, 101233. [CrossRef]

65. Yap, Y.L.; Wang, C.; Sing, S.L.; Dikshit, V.; Yeong, W.Y.; Wei, J. Material jetting additive manufacturing: An experimental study using designed metrological benchmarks. Precis. Eng. 2017, 50, 275-285. [CrossRef]

66. Material Jetting (PolyJet) 3D Printing: Everything You Need to Know. Available online: https://3dsourced.com/guides/polyjet/ (accessed on 11 November 2020).

67. Vu, I.Q.; Bass, L.B.; Williams, C.B.; Dillard, D.A. Characterizing the effect of print orientation on interface integrity of multimaterial jetting additive manufacturing. Addit. Manuf. 2018, 22, 447-461. [CrossRef]

68. Vu, I.; Bass, L.; Meisel, N.; Orler, B.; Williams, C.B.; Dillard, D.A. Characterization of mutli-material interfaces in polyjet additive manufacturing. In Proceedings of the 2015 International Solid Freeform Fabrication Symposium, Austin, TX, USA, 10-12 August 2015; pp. 959-982.

69. Pugalendhi, A.; Ranganathan, R.; Ganesan, S. Impact of process parameters on mechanical behaviour in multi-material jetting Mater. Today Proc. 2021, 46, 9139-9144. [CrossRef]

70. The Complete Guide to Material Jetting (PolyJet) in 3D Printing-3D Natives. Available online: https://www.3dnatives.com/en/ polyjet100420174/\#! (accessed on 5 November 2021).

71. Rocha, V.G.; Saiz, E.; Tirichenko, I.S.; García-Tuñón, E. Direct ink writing advances in multi-material structures for a sustainable future. J. Mater. Chem. A 2020, 8, 15646-15657. [CrossRef]

72. Joung, D.; Truong, V.; Neitzke, C.C.; Guo, S.Z.; Walsh, P.J.; Monat, J.R.; Meng, F.; Park, S.H.; Dutton, J.R.; Parr, A.M.; et al. 3D Printed Stem-Cell Derived Neural Progenitors Generate Spinal Cord Scaffolds. Adv. Funct. Mater. 2018, 28, 1801850. [CrossRef]

73. Kolesky, D.B.; Truby, R.L.; Gladman, A.S.; Busbee, T.A.; Homan, K.A.; Lewis, J.A. 3D bioprinting of vascularized, heterogeneous cell-laden tissue constructs. Adv. Mater. 2014, 26, 3124-3130. [CrossRef]

74. Schaffner, M.; Faber, J.A.; Pianegonda, L.; Rühs, P.A.; Coulter, F.; Studart, A.R. 3D printing of robotic soft actuators with programmable bioinspired architectures. Nat. Commun. 2018, 9, 878. [CrossRef]

75. Saed, M.O.; Ambulo, C.P.; Kim, H.; De, R.; Raval, V.; Searles, K.; Siddiqui, D.A.; Michael Cue, J.; Stefan, M.C.; Ravi Shankar, M.; et al. Molecularly-engineered, 4D-Printed liquid crystal elastomer actuators. Adv. Funct. Mater. 2019, 29, 1806412. [CrossRef]

76. Hyun Park, S.; Su, R.; Jeong, J.; Guo, S.-Z.; Qiu, K.; Joung, D.; Meng, F.; McAlpine, M.C.; Park, S.H.; Su, R.; et al. 3D printed polymer photodetectors. Adv. Mater. 2018, 30, 1803980. [CrossRef]

77. Wei, T.-S.; Ahn, B.Y.; Grotto, J.; Lewis, J.A.; Lewis, A.; Wei, T.-S.; Ahn, B.Y.; Grotto, J.; Paulson, J.A. 3D printing of customized Li-ion batteries with thick electrodes. Adv. Mater. 2018, 30, 1703027. [CrossRef]

78. Kokkinis, D.; Bouville, F.; Studart, A.R. 3D Printing of Materials with Tunable Failure via Bioinspired Mechanical Gradients. Adv. Mater. 2018, 30, 1705808. [CrossRef] 
79. Hardin, J.O.; Ober, T.J.; Valentine, A.D.; Lewis, J.A. Microfluidic printheads for multimaterial 3D printing of viscoelastic inks. Adv. Mater. 2015, 27, 3279-3284. [CrossRef]

80. Pelz, J.S.; Ku, N.; Shoulders, W.T.; Meyers, M.A.; Vargas-Gonzalez, L.R. Multi-material additive manufacturing of functionally graded carbide ceramics via active, in-line mixing. Addit. Manuf. 2021, 37, 101647. [CrossRef]

81. Gibson, I.; Rosen, D.; Stucker, B.; Gibson, I.; Rosen, D.; Stucker, B. Vat Photopolymerization Processes. In Additive Manufacturing Technologies; Springer: New York, NY, USA, 2015; pp. 63-106.

82. Bagheri, A.; Jin, J. Photopolymerization in 3D Printing. ACS Appl. Polym. Mater. 2019, 1, 593-611. [CrossRef]

83. Chan, V.; Jeong, J.H.; Bajaj, P.; Collens, M.; Saif, T.; Kong, H.; Bashir, R. Multi-material bio-fabrication of hydrogel cantilevers and actuators with stereolithography. Lab Chip 2012, 12, 88-98. [CrossRef]

84. Choi, J.W.; Kim, H.C.; Wicker, R. Multi-material stereolithography. J. Mater. Process. Technol. 2011, 211, 318-328. [CrossRef]

85. Yan, J.; Masoudi, N.; Battiato, I.; Fadel, G. Optimization of Process Parameters in Laser Engineered Net Shaping (LENS) Deposition of Multi-Materials. In Proceedings of the International Design Engineering Technical Conferences and Computers and Information in Engineering Conference, Boston, MA, USA, 2-5 August 2015; p. V01AT02A034. [CrossRef]

86. Dass, A.; Moridi, A. State of the Art in Directed Energy Deposition: From Additive Manufacturing to Materials Design. Coatings 2019, 9, 418. [CrossRef]

87. Saboori, A.; Gallo, D.; Biamino, S.; Fino, P.; Lombardi, M. An overview of additive manufacturing of titanium components by directed energy deposition: Microstructure and mechanical properties. Appl. Sci. 2017, 7, 883. [CrossRef]

88. Thompson, S.M.; Bian, L.; Shamsaei, N.; Yadollahi, A. An overview of Direct Laser Deposition for additive manufacturing; Part I: Transport phenomena, modeling and diagnostics. Addit. Manuf. 2015, 8, 36-62. [CrossRef]

89. Zhang, C.; Chen, F.; Huang, Z.; Jia, M.; Chen, G.; Ye, Y.; Lin, Y.; Liu, W.; Chen, B.; Shen, Q.; et al. Additive manufacturing of functionally graded materials: A review. Mater. Sci. Eng. A 2019, 764, 138209. [CrossRef]

90. Ke, D.; Vu, A.A.; Bandyopadhyay, A.; Bose, S. Compositionally graded doped hydroxyapatite coating on titanium using laser and plasma spray deposition for bone implants. Acta Biomater. 2019, 84, 414-423. [CrossRef]

91. Fousová, M.; Vojtěch, D.; Kubásek, J.; Jablonská, E.; Fojt, J. Promising characteristics of gradient porosity Ti-6Al-4V alloy prepared by SLM process. J. Mech. Behav. Biomed. Mater. 2017, 69, 368-376. [CrossRef]

92. Choy, S.Y.; Sun, C.N.; Leong, K.F.; Wei, J. Compressive properties of functionally graded lattice structures manufactured by selective laser melting. Mater. Des. 2017, 131, 112-120. [CrossRef]

93. del Val, J.; Arias-González, F.; Barro, O.; Riveiro, A.; Comesaña, R.; Penide, J.; Lusquiños, F.; Bountinguiza, M.; Quintero, F.; Pou, J. Functionally graded 3D structures produced by laser cladding. Procedia Manuf. 2017, 13, 169-176. [CrossRef]

94. Pragana, J.P.M.; Sampaio, R.F.V.; Bragança, I.M.F.; Silva, C.M.A.; Martins, P.A.F. Hybrid metal additive manufacturing: A state-of-the-art review. Adv. Ind. Manuf. Eng. 2021, 2, 100032. [CrossRef]

95. Roach, D.J.; Hamel, C.M.; Dunn, C.K.; Johnson, M.V.; Kuang, X.; Qi, H.J. The m4 3D printer: A multi-material multi-method additive manufacturing platform for future 3D printed structures. Addit. Manuf. 2019, 29, 100819. [CrossRef]

96. Lasertec 125: DMG Mori Releases New 3D Hybrid System for Maintaining \& Repairing Parts. Available online: https:// 3dprint.com/260887/lasertec-125-dmg-mori-releases-new-3d-hybrid-system-maintaining-repairing-parts/ (accessed on 12 November 2021).

97. Hybrid Metal Manufacturing-A Core Application for Optomec Additive Manufacturing Solutions. Available online: http: / / optomec.com/3d-printed-metals/lens-core-applications/hybrid-manufacturing/ (accessed on 19 November 2021).

98. Flynn, J.M.; Shokrani, A.; Newman, S.T.; Dhokia, V. Hybrid additive and subtractive machine tools-Research and industrial developments. Int. J. Mach. Tools Manuf. 2016, 101, 79-101. [CrossRef]

99. Loh, G.H.; Pei, E. Building a Conceptual Understanding of Functionally Graded Additive Manufacturing (FGAM) and Its Limitations. In Proceedings of the 15th Rapid Design, Prototyping \& Manufacturing Conference (RDPM 2017), Newcastle, UK, 27-28 April 2017.

100. Li, J.; Stachowski, M.; Zhang, Z. Application of responsive polymers in implantable medical devices and biosensors. In Switchable and Responsive Surfaces and Materials for Biomedical Applications; Elsevier Inc.: Amsterdam, The Netherlands, 2015; pp. 259-298. ISBN 9780857097170.

101. Hasanov, S. Numerical Modeling and Experimental Characterization of Functionally Fraded Materials Manufactured by the Fused Filament Fabrication Process. Ph.D. Thesis, Tennessee Technological University, Cookeville, TN, USA, 2021.

102. Hasanov, S.; Gupta, A.; Alifui-Segbaya, F.; Fidan, I. Hierarchical homogenization and experimental evaluation of functionally graded materials manufactured by the fused filament fabrication process. Compos. Struct. 2021, 275, 114488. [CrossRef]

103. Nasirov, A.; Gupta, A.; Hasanov, S.; Fidan, I. Three-scale asymptotic homogenization of short fiber reinforced additively manufactured polymer composites. Compos. Part B Eng. 2020, 202, 108269. [CrossRef]

104. GraMMaCAD—Graded Multi-Material CAD. Available online: https://www.igd.fraunhofer.de/en/projects/grammacadgraded-multi-material-cad (accessed on 7 November 2021).

105. Luu, T.H.; Altenhofen, C.; Ewald, T.; Stork, A.; Fellner, D. Efficient slicing of Catmull-Clark solids for 3D printed objects with functionally graded material. Comput. Graph. 2019, 82, 295-303. [CrossRef]

106. Espalin, D.; Muse, D.W.; MacDonald, E.; Wicker, R.B. 3D Printing multifunctionality: Structures with electronics. Int. J. Adv. Manuf. Technol. 2014, 72, 963-978. [CrossRef] 
107. Chen, Z.; Li, Z.; Li, J.; Liu, C.; Lao, C.; Fu, Y.; Liu, C.; Li, Y.; Wang, P.; He, Y. 3D printing of ceramics: A review. J. Eur. Ceram. Soc. 2019, 39, 661-687. [CrossRef]

108. Kumar, S.; Singh, R.; Singh, M. Multi-material 3D printed PLA/PA6-TiO2 composite matrix: Rheological, thermal, tensile, morphological and 4D capabilities. Adv. Mater. Process. Technol. 2021, 1-19. [CrossRef]

109. PC-ABS: A Heat Resistant 3D Printing Material. Available online: https:/ / www.stratasys.com/materials/search/pc-abs (accessed on 17 November 2020).

110. Ahn, S.H.; Montero, M.; Odell, D.; Roundy, S.; Wright, P.K. Anisotropic material properties of fused deposition modeling ABS. Rapid Prototyp. J. 2002, 8, 248-257. [CrossRef]

111. Sa'ude, N.; Masood, S.H.; Nikzad, M.; Ibrahim, M. Dynamic Mechanical Properties of Copper-ABS Composites for FDM Feedstock. Int. J. Eng. Res. Appl. 2013, 3, 1257-1263.

112. Rohde, S.; Cantrell, J.; Jerez, A.; Kroese, C.; Damiani, D.; Gurnani, R.; DiSandro, L.; Anton, J.; Young, A.; Steinbach, D.; et al. Experimental Characterization of the Shear Properties of 3D-Printed ABS and Polycarbonate Parts. Exp. Mech. 2018, 58, 871-884. [CrossRef]

113. Kumar, R.; Singh, R.; Farina, I. On the 3D printing of recycled ABS, PLA and HIPS thermoplastics for structural applications. PSU Res. Rev. 2018, 2, 115-137. [CrossRef]

114. Afshar, A.; Wood, R. Development of Weather-Resistant 3D Printed Structures by Multi-Material Additive Manufacturing. J. Compos. Sci. 2020, 4, 94. [CrossRef]

115. Kluczyński, J.; Śnieżek, L.; Kravcov, A.; Grzelak, K.; Svoboda, P.; Szachogłuchowicz, I.; Franek, O.; Morozov, N.; Torzewski, J.; Kubeček, P. The Examination of Restrained Joints Created in the Process of Multi-Material FFF Additive Manufacturing Technology. Materials 2020, 13, 903. [CrossRef] [PubMed]

116. Wagner, M.A.; Huang, J.-L.; Okle, P.; Paik, J.; Spolenak, R. Hinges for origami-inspired structures by multimaterial additive manufacturing. Mater. Des. 2020, 191, 108643. [CrossRef]

117. Otepbergenov, T.; Smagulov, Z.; Abilgaziyev, A.; Kurokawa, S.; Ali, M.H. Numerical and experimental analysis of the 3D printed multi-material ankle-foot orthosis. J. Phys. Conf. Ser. 2020, 1510, 012012. [CrossRef]

118. Dey, A.; Roan Eagle, I.N.; Yodo, N. A Review on Filament Materials for Fused Filament Fabrication. J. Manuf. Mater. Process. 2021, 5, 69. [CrossRef]

119. Farah, S.; Anderson, D.G.; Langer, R. Physical and mechanical properties of PLA, and their functions in widespread applications - A comprehensive review. Adv. Drug Deliv. Rev. 2016, 107, 367-392. [CrossRef] [PubMed]

120. Polyetheretherketone (PEEK). Available online: https://www.makeitfrom.com/material-properties/Polyetheretherketone-PEEK (accessed on 2 November 2021).

121. Jiang, S.; Liao, G.; Xu, D.; Liu, F.; Li, W.; Cheng, Y.; Li, Z.; Xu, G. Mechanical properties analysis of polyetherimide parts fabricated by fused deposition modeling. High Perform. Polym. 2018, 31, 97-106. [CrossRef]

122. Polyamide (PA, Nylon) 11. Available online: https://www.makeitfrom.com/material-properties/Polyamide-PA-Nylon-11 (accessed on 2 November 2021).

123. Kim, D.K.; Woo, W.; Kim, E.Y.; Choi, S.H. Microstructure and mechanical characteristics of multi-layered materials composed of 316L stainless steel and ferritic steel produced by direct energy deposition. J. Alloys Compd. 2019, 774, 896-907. [CrossRef]

124. Udupa, G.; Rao, S.S.; Gangadharan, K.V. Functionally Graded Composite Materials: An Overview. Procedia Mater. Sci. 2014, 5 , 1291-1299. [CrossRef]

125. Zhuang, Y.; Song, W.; Ning, G.; Sun, X.; Sun, Z.; Xu, G.; Zhang, B.; Chen, Y.; Tao, S. 3D-printing of materials with anisotropic heat distribution using conductive polylactic acid composites. Mater. Des. 2017, 126, 135-140. [CrossRef]

126. Nasirov, A.; Fidan, I. Prediction of mechanical properties of fused filament fabricated structures via asymptotic homogenization. Mech. Mater. 2020, 145, 103372. [CrossRef]

127. Mohammadizadeh, M.; Gupta, A.; Fidan, I. Mechanical benchmarking of additively manufactured continuous and short carbon fiber reinforced nylon. J. Compos. Mater. 2021. [CrossRef]

128. Christ, J.; Aliheidari, N.; Pötschke, P.; Ameli, A. Bidirectional and Stretchable Piezoresistive Sensors Enabled by Multimaterial 3D Printing of Carbon Nanotube/Thermoplastic Polyurethane Nanocomposites. Polymers 2018, 11, 11. [CrossRef] [PubMed]

129. García-Macías, E.; Rodríguez-Tembleque, L.; Castro-Triguero, R.; Sáez, A. Eshelby-Mori-Tanaka approach for post-buckling analysis of axially compressed functionally graded CNT/polymer composite cylindrical panels. Compos. Part B Eng. 2017, 128, 208-224. [CrossRef]

130. Fu, Y.; Xu, G.; Chen, Z.; Liu, C.; Wang, D.; Lao, C. Multiple metals doped polymer-derived SiOC ceramics for 3D printing. Ceram. Int. 2018, 44, 11030-11038. [CrossRef]

131. Gualtieri, T.; Bandyopadhyay, A. Additive manufacturing of compositionally gradient metal-ceramic structures: Stainless steel to vanadium carbide. Mater. Des. 2018, 139, 419-428. [CrossRef]

132. Krella, A.; Czyzniewski, A. Cavitation erosion resistance of $\mathrm{Cr}-\mathrm{N}$ coating deposited on stainless steel. Wear 2006, $260,1324-1332$. [CrossRef]

133. Zhang, Y.; Sahasrabudhe, H.; Bandyopadhyay, A. Additive manufacturing of Ti-Si-N ceramic coatings on titanium. Appl. Surf. Sci. 2015, 346, 428-437. [CrossRef]

134. Kattire, P.; Paul, S.; Singh, R.; Yan, W. Experimental characterization of laser cladding of CPM 9 V on H13 tool steel for die repair applications. J. Manuf. Process. 2015, 20, 492-499. [CrossRef] 
135. Ceramic Matrix Composites. Available online: https://www.library.ucdavis.edu/wp-content/uploads/2016/12/HDBK17-5.pdf (accessed on 20 November 2021).

136. Pavlov, M.; Novichenko, D.; Doubenskaia, M. Optical Diagnostics of Deposition of Metal Matrix Composites by Laser Cladding. Phys. Procedia 2011, 12, 674-682. [CrossRef]

137. Zhang, D.; Jonhson, W.; Herng, T.S.; Xu, X.; Liu, X.; Pan, L.; He, H.; Ding, J. High Temperature Co-firing of 3D-Printed $\mathrm{Al}-\mathrm{ZnO} / \mathrm{Al} 2 \mathrm{O} 3 \mathrm{Multi}-\mathrm{Material}$ Two-Phase Flow Sensor. J. Mater. 2021. [CrossRef]

138. Gheisari, R.; Chamberlain, H.; Chi-Tangyie, G.; Zhang, S.; Goulas, A.; Lee, C.-K.; Whittaker, T.; Wang, D.; Ketharam, A.; Ghosh, A.; et al. Multi-material additive manufacturing of low sintering temperature Bi 2 Mo $2 \mathrm{O} 9$ ceramics with Ag floating electrodes by selective laser burnout. Virtual Phys. Prototyp. 2020, 15, 133-147. [CrossRef]

139. Das, M.; Balla, V.K.; Basu, D.; Bose, S.; Bandyopadhyay, A. Laser processing of SiC-particle-reinforced coating on titanium. Scr. Mater. 2010, 63, 438-441. [CrossRef]

140. Heer, B.; Bandyopadhyay, A. Compositionally graded magnetic-nonmagnetic bimetallic structure using laser engineered net shaping. Mater. Lett. 2018, 216, 16-19. [CrossRef]

141. Mohd Yusuf, S.; Zhao, X.; Yang, S.; Gao, N. Interfacial characterisation of multi-material 316L stainless steel/Inconel 718 fabricated by laser powder bed fusion. Mater. Lett. 2021, 284, 128928. [CrossRef]

142. Tan, C.; Wang, D.; Ma, W.; Zhou, K. Ultra-strong bond interface in additively manufactured iron-based multi-materials. Mater. Sci. Eng. A 2021, 802, 140642. [CrossRef]

143. Sing, S.L.L.; Lam, L.P.P.; Zhang, D.Q.Q.; Liu, Z.H.H.; Chua, C.K.K. Interfacial characterization of SLM parts in multi-material processing: Intermetallic phase formation between AlSi10Mg and C18400 copper alloy. Mater. Charact. 2015, 107, 220-227. [CrossRef]

144. Demir, A.G.; Previtali, B. Multi-material selective laser melting of Fe/Al-12Si components. Manuf. Lett. 2017, 11, 8-11. [CrossRef]

145. Singh, S.; Singh, R. Development of functionally graded material by fused deposition modelling assisted investment casting. $J$. Manuf. Process. 2016, 24, 38-45. [CrossRef]

146. Tan, C.; Zhou, K.; Kuang, T. Selective laser melting of tungsten-copper functionally graded material. Mater. Lett. 2019, 237, 328-331. [CrossRef]

147. Xiang, W.; Xuliang, M.; Xinlin, L.; Lihua, D.; Mingjia, W. Effect of boron addition on microstructure and mechanical properties of TiC/Ti6Al4V composites. Mater. Des. 2012, 36, 41-46. [CrossRef]

148. Li, L.; Wang, J.; Lin, P.; Liu, H. Microstructure and mechanical properties of functionally graded TiCp/Ti6Al4V composite fabricated by laser melting deposition. Ceram. Int. 2017, 43, 16638-16651. [CrossRef]

149. Lu, Y.; Tang, H.B.; Fang, Y.L.; Liu, D.; Wang, H.M. Microstructure evolution of sub-critical annealed laser deposited Ti-6Al-4V alloy. Mater. Des. 2012, 37, 56-63. [CrossRef]

150. Bobbio, L.D.; Bocklund, B.; Otis, R.; Borgonia, J.P.; Dillon, R.P.; Shapiro, A.A.; McEnerney, B.; Liu, Z.K.; Beese, A.M. Characterization of a functionally graded material of Ti-6Al-4V to $304 \mathrm{~L}$ stainless steel with an intermediate V section. J. Alloys Compd. 2018, 742, 1031-1036. [CrossRef]

151. Bobbio, L.D.; Otis, R.A.; Borgonia, J.P.; Dillon, R.P.; Shapiro, A.A.; Liu, Z.K.; Beese, A.M. Additive manufacturing of a functionally graded material from Ti-6Al-4V to Invar: Experimental characterization and thermodynamic calculations. Acta Mater. 2017, 127, 133-142. [CrossRef]

152. Schneider-Maunoury, C.; Weiss, L.; Acquier, P.; Boisselier, D.; Laheurte, P. Functionally graded Ti6Al4V-Mo alloy manufactured with DED-CLADRprocess. Addit. Manuf. 2017, 17, 55-66. [CrossRef]

153. Zhang, Y.; Bandyopadhyay, A. Direct fabrication of compositionally graded Ti-Al2O3 multi-material structures using Laser Engineered Net Shaping. Addit. Manuf. 2018, 21, 104-111. [CrossRef]

154. Niendorf, T.; Leuders, S.; Riemer, A.; Brenne, F.; Tröster, T.; Richard, H.A.; Schwarze, D. Functionally Graded Alloys Obtained by Additive Manufacturing. Adv. Eng. Mater. 2014, 16, 857-861. [CrossRef]

155. Yakovlev, A.; Trunova, E.; Grevey, D.; Pilloz, M.; Smurov, I. Laser-assisted direct manufacturing of functionally graded 3D objects. Surf. Coat. Technol. 2005, 190, 15-24. [CrossRef]

156. Woo, W.; Kim, D.K.; Kingston, E.J.; Luzin, V.; Salvemini, F.; Hill, M.R. Effect of interlayers and scanning strategies on throughthickness residual stress distributions in additive manufactured ferritic-austenitic steel structure. Mater. Sci. Eng. A 2019, 744, 618-629. [CrossRef]

157. Trivedi, D.; Rahn, C.D.; Kier, W.M.; Walker, I.D. Soft robotics: Biological inspiration, state of the art, and future research. Appl. Bionics Biomech. 2008, 5, 99-117. [CrossRef]

158. JZ, G.; M, S.; MM, R.; GU, S.; I, S.; KH, K.; JW, L.; KH, C. 3D printing for soft robotics - a review. Sci. Technol. Adv. Mater. 2018, 19, 243-262. [CrossRef]

159. Wallin, T.J.; Pikul, J.; Shepherd, R.F. 3D printing of soft robotic systems. Nat. Rev. Mater. 2018, 3, 84-100. [CrossRef]

160. Venumbaka, S.A.; Covarubias, M.; Cesaro, G.; Ronca, A.; De Capitani, C.; Ambrosio, L.; Sorrentino, A. Application of Multi Materials Additive Manufacturing Technique in the Design and Manufacturing of Hand Orthoses. In Proceedings of the International Conference on Computers Helping People with Special Needs LNCS, Lecco, Italy, 9-11 September 2020; pp. 461-468. [CrossRef]

161. 3D Printing Applications for Medical Education. Available online: https://www.stratasys.com/explore/whitepaper/3d-printingclinical-simulation (accessed on 2 November 2021). 
162. Lithoz Shows Off Multi-Material Ceramics 3D Printing on CeraFab Multi 2M30. Available online: https://www.3dprintingmedia. network/multi-material-ceramics-3d-printing-on-cerafab-multi-2m30/ (accessed on 6 November 2021).

163. Anatomical Model Parts on Demand with 3D Printing. Available online: https://www.stratasysdirect.com/applications/ anatomical-models (accessed on 20 November 2021).

164. 3D Design Futures: An Interview with Dr. Daniel Richards, Part 2. Available online: https://www.fabbaloo.com/2018/01/3ddesign-futures-an-interview-with-dr-daniel-richards-part-2 (accessed on 6 November 2021).

165. Cámara-Torres, M.; Duarte, S.; Sinha, R.; Egizabal, A.; Álvarez, N.; Bastianini, M.; Sisani, M.; Scopece, P.; Scatto, M.; Bonetto, A.; et al. 3D additive manufactured composite scaffolds with antibiotic-loaded lamellar fillers for bone infection prevention and tissue regeneration. Bioact. Mater. 2021, 6, 1073. [CrossRef]

166. Fanfoni, L.; Marsich, E.; Turco, G.; Breschi, L.; Cadenaro, M. Development of di-methacrylate quaternary ammonium monomers with antibacterial activity. Acta Biomater. 2021, 129, 138-147. [CrossRef]

167. Bishop, E.S.; Mostafa, S.; Pakvasa, M.; Luu, H.H.; Lee, M.J.; Wolf, J.M.; Ameer, G.A.; He, T.C.; Reid, R.R. 3-D bioprinting technologies in tissue engineering and regenerative medicine: Current and future trends. Genes Dis. 2017, 4, 185-195. [CrossRef] [PubMed]

168. Lind, J.U.; Busbee, T.A.; Valentine, A.D.; Pasqualini, F.S.; Yuan, H.; Yadid, M.; Park, S.J.; Kotikian, A.; Nesmith, A.P.; Campbell, P.H.; et al. Instrumented cardiac microphysiological devices via multimaterial three-dimensional printing. Nat. Mater. 2017, 16, 303-308. [CrossRef]

169. Tan, Y.J.N.; Yong, W.P.; Low, H.R.; Kochhar, J.S.; Khanolkar, J.; Lim, T.S.E.; Sun, Y.; Wong, J.Z.E.; Soh, S. Customizable drug tablets with constant release profiles via 3D printing technology. Int. J. Pharm. 2021, 598. [CrossRef] [PubMed]

170. Mitchell, A.; Lafont, U.; Hołyńska, M.; Semprimoschnig, C. Additive manufacturing-A review of 4D printing and future applications. Addit. Manuf. 2018, 24, 606-626. [CrossRef]

171. Joshi, S.; Rawat, K.; Karunakaran, C.; Rajamohan, V.; Mathew, A.T.; Koziol, K.; Kumar Thakur, V.; Balan, A.S.S. 4D printing of materials for the future: Opportunities and challenges. Appl. Mater. Today 2020, 18, 100490. [CrossRef]

172. Lumpe, T.S.; Mueller, J.; Shea, K. Tensile properties of multi-material interfaces in 3D printed parts. Mater. Des. 2019, 162, 1-9. [CrossRef]

173. Bartlett, N.W.; Tolley, M.T.; Overvelde, J.T.B.; Weaver, J.C.; Mosadegh, B.; Bertoldi, K.; Whitesides, G.M.; Wood, R.J. A 3D-printed, functionally graded soft robot powered by combustion. Science 2015, 349, 161-165. [CrossRef]

174. Brackett, J.; Yan, Y.; Cauthen, D.; Kishore, V.; Lindahl, J.; Smith, T.; Sudbury, Z.; Ning, H.; Kunc, V.; Duty, C. Characterizing material transitions in large-scale Additive Manufacturing. Addit. Manuf. 2021, 38, 101750. [CrossRef]

175. Sudbury, Z.; Duty, C.; Kunc, V. Expanding material property space maps with functionally graded materials for large scale additive manufacturing. In Proceedings of the 2017 International Solid Freeform Fabrication Symposium, Austin, TX, USA, 7-9 August 2017; Volume 5, pp. 459-469.

176. Hofmann, D.C.; Roberts, S.; Otis, R.; Kolodziejska, J.; Dillon, R.P.; Suh, J.O.; Shapiro, A.A.; Liu, Z.K.; Borgonia, J.P. Developing gradient metal alloys through radial deposition additive manufacturing. Sci. Rep. 2014, 4, 5357. [CrossRef]

177. Freund, R.; Watschke, H.; Heubach, J.; Vietor, T. Determination of Influencing Factors on Interface Strength of Additively Manufactured Multi-Material Parts by Material Extrusion. Appl. Sci. 2019, 9, 1782. [CrossRef]

178. Ezair, B.; Dikovsky, D.; Elber, G. Fabricating Functionally Graded Material Objects Using Trimmed Trivariate Volumetric Representations. In Proceedings of the Shape Modeling International (SMI-2017) Symposium, Berkeley, CA, USA, 21-23 June 2017.

179. Kuipers, T.; Su, R.; Wu, J.; Wang, C.C.L. ITIL: Interlaced Topologically Interlocking Lattice for continuous dual-material extrusion. Addit. Manuf. 2022, 50, 102495. [CrossRef]

180. Stoner, B.; Bartolai, J.; Kaweesa, D.V.; Meisel, N.A.; Simpson, T.W. Achieving Functionally Graded Material Composition Through Bicontinuous Mesostructural Geometry in Material Extrusion Additive Manufacturing. JOM 2018, 70, 413-418. [CrossRef]

181. Muller, P.; Mognol, P.; Hascoet, J.Y. Functionally Graded Material (FGM) Parts: From Design to the Manufacturing Simulation. In Proceedings of the ASME 2012 11th Biennial Conference on Engineering Systems Design and Analysis, Nantes, France, 2-4 July 2012; pp. 123-131. [CrossRef]

182. Ponche, R.; Hascoët, J.-Y.; Kerbrat, O.; Mognol, P. A new global approach to design for additive manufacturing: A method to obtain a design that meets specifications while optimizing a given additive manufacturing. Virtual Phys. Prototyp. 2012, 7, 93-105. [CrossRef]

183. Saleh, B.; Jiang, J.; Fathi, R.; Al-hababi, T.; Xu, Q.; Wang, L.; Song, D.; Ma, A. 30 Years of functionally graded materials: An overview of manufacturing methods, Applications and Future Challenges. Compos. Part B Eng. 2020, 201, 108376. [CrossRef]

184. Kim, H.; Park, E.; Kim, S.; Park, B.; Kim, N.; Lee, S. Experimental Study on Mechanical Properties of Single- and Dual-material 3D Printed Products. Procedia Manuf. 2017, 10, 887-897. [CrossRef]

185. Roger, F.; Krawczak, P. 3D-printing of thermoplastic structures by FDM using heterogeneous infill and multi-materials: An integrated design-advanced manufacturing approach for factories of the future. Abstr. Struct. Multidiscip. Optim. 2015, 50, 1-7. [CrossRef]

186. Brackett, J.; Yan, Y.; Cauthen, D.; Kishore, V.; Lindahl, J. Development of Functionally Graded Material Capabilities in Large-scale Extrusion Deposition Additive Manufacturing. In Proceedings of the 30th Annual International Solid Freeform Fabrication Symposium-An Additive Manufacturing Conference, Austin, TX, USA, 12-14 August 2019; pp. 1793-1803. 
187. Lopes, L.R.; Silva, A.F.; Carneiro, O.S. Multi-material 3D printing: The relevance of materials affinity on the boundary interface performance. Addit. Manuf. 2018, 23, 45-52. [CrossRef]

188. Mueller, J.; Courty, D.; Spielhofer, M.; Spolenak, R.; Shea, K. Mechanical Properties of Interfaces in Inkjet 3D Printed Single- and Multi-Material Parts. 3D Print. Addit. Manuf. 2017, 4, 193-199. [CrossRef]

189. Sundaram, S.; Skouras, M.; Kim, D.S.; van den Heuvel, L.; Matusik, W. Topology optimization and 3D printing of multimaterial magnetic actuators and displays. Sci. Adv. 2019, 5, eaaw1160. [CrossRef] 